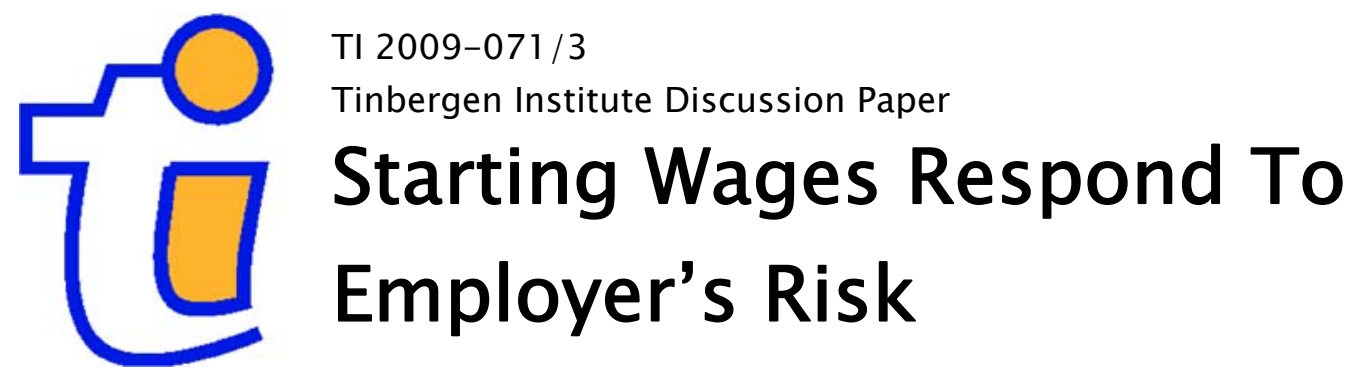

Peter Berkhout ${ }^{1}$

Joop Hartog 2,3

Hans van Ophem²

' EIB Amsterdam;

2 University of Amsterdam;

3 Tinbergen Institute. 


\section{Tinbergen Institute}

The Tinbergen Institute is the institute for economic research of the Erasmus Universiteit Rotterdam, Universiteit van Amsterdam, and Vrije Universiteit Amsterdam.

Tinbergen Institute Amsterdam

Roetersstraat 31

1018 WB Amsterdam

The Netherlands

Tel.: +31(0)205513500

Fax: $+31(0) 205513555$

Tinbergen Institute Rotterdam

Burg. Oudlaan 50

3062 PA Rotterdam

The Netherlands

Tel.: + $31(0) 104088900$

Fax: $+31(0) 104089031$

Most TI discussion papers can be downloaded at http://www.tinbergen.nl. 


\title{
STARTING WAGES RESPOND TO EMPLOYER'S RISK
}

\author{
peter berkhout \\ EIB Amsterdam \\ joop hartog \\ hans van ophem \\ Universiteit van Amsterdam
}

JEL code: J31

Keywords: wages; risk compensation; ability; incomplete information

\section{Abstract}

Firms hiring fresh graduates face uncertainty on the future productivity of workers. Theory suggests that starting wages reflect this, with lower pay for greater uncertainty. We use the dispersion of exam grades within a field of education as an indicator of the unobserved heterogeneity that employers face. We find solid evidence that starting wages are lower if the variance of exam grades is higher and higher if the skew is higher: employers shift the cost of productivity risk to new hires, but pay for the opportunity to catch a really good worker. Estimating the extent of risk cost sharing between firm and worker shows that shifting to workers is larger in the market sector than in the public sector and diminishes with experience.

Hartog acknowledges financial support from the Spanish Ministry of Science and Innovation through grant SEJ2007-66318. Comments by George Baker are gratefully acknowledged.

First draft: 22 March 2006; this draft 06 August 2009; file: Starting wage employer riskIZARevisedTI060809. This is a substantial revision of our IZA DP 3026. 


\section{Introduction}

An employer hiring a new employee fresh from school has no more than imperfect information on the worker's qualities. The diploma itself, some information on school grades, extracurricular activities, a job interview and perhaps a psychological test cannot fully resolve the uncertainty about future productivity. Firms may be expected to bill the workers for the cost of dealing with this uncertainty. Workers fresh from school have no successes yet to support a bargaining position and will have to accept that employers put a discount on starting wages in accordance with the risk they face. Thus, we predict that starting wages will be lower in fields where employers face more uncertainty on any individual's productivity. However, we also predict that starting wages will be higher if employers perceive more skewness in the productivity distribution: they appreciate the chance to catch an individual with very high productivity. We find clear support for these predictions.

We use the distribution of exam grades within a field to measure uncertainty. If the variance of exam grades across graduates in economics is larger than across graduates in physics, employers can make less accurate predictions on the productivity of an individual economist than on the productivity of an individual physicist. Our core hypothesis is that wages will reflect these differences in risk. More specifically, we predict that wages will respond negatively to the variance of exam grades in a field (workers pay a risk premium) and positively to the skew of the exam grades in a field (firms appreciate the upside risk of hitting upon a very good worker). This hypothesis is supported by a large sample of starting salaries for graduates from tertiary education in The Netherlands.

To back up our intuitive argument, we formally model the employer's wage offer function. It is commonly assumed that workers are risk averse and firms are risk neutral. This is probably pushing the case too far. It is quite likely that on average workers are more risk averse than firms, but no doubt firms are also risk averse. Small firms may have every reason to behave as risk averters, as they often lack the resources to survive bad draws. But large firms are also observed to engage in buying all kinds of insurances, for failing debtors, worker safety hazards, currency fluctuations, etc ${ }^{1}$. There is sufficient evidence to assume that firms are risk averse. Our prediction on the wage effect of productivity variance is similar to Freeman (1977) and to Harris and Holmstrom (1982) ${ }^{2}$. They specified models in which firms are risk neutral and sell insurance to risk averse workers who do not like the risk of a decline in wages when after a while initial uncertainty about a worker's productivity is resolved. The present paper is the first to attempt a direct empirical test of this prediction.

\footnotetext{
${ }^{1}$ To witness: Dutch electronics multinational Philips sells its chips division because sales and profits vary too much over the business cycle (NRC, August 4, 2006).

2 Altonji and Pierret (2001) and Farber and Gibbons (1996) also analyse the effect of imperfect information on wages for starting workers; they focus on the role of variables that are not available or not used by employers (such as test scores and school grades) that have increasing impact on wages as experience accumulates, because they relate to ability and ability increasingly influences wages.
} 
Our model also predicts a positive effect on wages of the third moment of the ability or productivity distribution. Allowing for an effect of skewness is not routinely considered in labour market applications, but is well known in the lifecycle consumption-savings literature and also applied in Hartog and Vijverberg (2007). The latter paper focuses on compensation to workers for the financial risk of an education (an education gives access to a distribution of wages, not to a single wage rate), and provides a good backdrop for the present analysis: in a sense it is the mirror image of the case we study here. Complementarity of these two cases means that the results of these tests reinforce each other.

In the next section, we derive our predictions formally. In section 3 we present the data, in section 4 we show the results. Section 5 considers robustness, section 6 estimates risk cost sharing between employers and workers, section 7 concludes.

\section{Formal arguments}

\subsection{A model for risk shifting}

Assume that individuals are characterized by their productivity. Firms can hire two types of workers, experienced and inexperienced. Productivity of experienced workers has been revealed with experience and is fully known to firms and there is a well-defined market wage function to reward this productivity. This is obviously a simplification, as in practice information develops gradually. In their decision what employees to hire, firms maximize the utility of profits by maximizing it across productivity $q_{i j}$. Productivity both depends on the individual (i) and the firm (j). Thus

$$
\max U\left(\Pi_{i j}\right)=U\left(p q_{i j}-w\left(q_{i j}\right)\right)
$$

where: $\Pi_{i j}=$ the profit earned on individual $\mathrm{i}$ if employed by firm $\mathrm{j}$ that is maximized across the productivity $q_{i j}$;

$p=$ price of output;

$w()=$. the market wage depending on the productivity of individual $i$ if employed by firm $\mathrm{j}$.

Solving this problem determines the optimal productivity $q_{i j}^{o}$ for firm $\mathrm{j}$.

If firms hire inexperienced workers, i.e. fresh graduates, they do not know individuals' true productivity. Instead, the firm has some perception $\widetilde{q}_{i j}$, the perceived productivity of individual $i$ if employed by firm $j$. The information is based on e.g. impressions collected during the application process, the evaluation of labour market activity while in school, extracurricular activities, etc. The firm deliberately searches for workers with optimal productivity as defined above; we assume that the firm's search and selection procedure leads to candidates with the proper expected productivity, but that perceived productivity deviates randomly from the optimum, i.e. 


$$
E\left(\widetilde{q}_{i j}\right)=q_{i j}^{o}
$$

In its decision to hire an individual or not the firm considers:

$$
U\left(p \tilde{q}_{i j}-\tilde{w}\left(\tilde{q}_{i j}\right)\right)
$$

This is the utility of profit on a worker with perceived productivity $\tilde{q}_{i j}$ and offered a wage commensurate with the uncertainty facing the firm. As the firm can hire experienced workers with known productivity, it will only hire inexperienced workers with uncertain productivity if the pay-offs are identical:

$$
E\left[U\left(p \tilde{q}_{i j}-\tilde{w}\left(\tilde{q}_{i j}\right)\right)\right]=U\left(p q_{i j}^{o}-w\left(q_{i j}^{o}\right)\right) .
$$

Firms will use the wage function $\tilde{w}\left(\tilde{q}_{i j}\right)$ to establish this equality between expected utility from hiring a new graduate with uncertain productivity or hiring an experienced worker with known productivity.

We can rewrite the right hand side of (4) by developing a Taylor expansion of utility from hiring a worker with uncertain productivity at the experienced market wage function around the utility from hiring an experienced worker, at the experienced market wage function:

$$
U\left(p \tilde{q}_{i j}-w\left(\tilde{q}_{i j}\right)\right)=U\left(p q_{i j}^{o}-w\left(q_{i j}^{o}\right)\right)+\left.\frac{\partial U}{\partial \tilde{q}_{i j}}\right|_{q_{i j}^{o}}\left(\tilde{q}_{i j}-q_{i j}^{o}\right)+\left.\frac{1}{2} \frac{\partial^{2} U}{\partial \tilde{q}_{i j}^{2}}\right|_{q_{i j}^{o}}\left(\tilde{q}_{i j}-q_{i j}^{o}\right)^{2}+\left.\frac{1}{6} \frac{\partial^{3} U}{\partial \tilde{q}_{i j}^{3}}\right|_{q_{i j}^{o}}\left(\tilde{q}_{i j}-q_{i j}^{o}\right)^{3}+R_{4}
$$

where $R_{4}$ collects the higher order terms, ignored from now on. Since $\widetilde{q}_{i j}$ is a random variable we need to assume that firm $\mathrm{j}$ actually considers expected profits in its decisions, so we get:

$$
\begin{aligned}
& E\left[U\left(p \tilde{q}_{i j}-w\left(\tilde{q}_{i j}\right)\right)\right]=E\left[U\left(p q_{i j}^{o}-w\left(q_{i j}^{o}\right)\right)\right]+\left.\frac{\partial U}{\partial \tilde{q}_{i j}}\right|_{q_{i j}^{o}} E\left[\left(\tilde{q}_{i j}-q_{i j}^{o}\right)\right]+\left.\frac{1}{2} \frac{\partial^{2} U}{\partial \tilde{q}_{i j}^{2}}\right|_{q_{i j}^{o}} E\left[\left(\tilde{q}_{i j}-q_{i j}^{o}\right)^{2}\right] \\
& +\left.\frac{1}{6} \frac{\partial^{3} U}{\partial \tilde{q}_{i j}^{3}}\right|_{q_{i j}^{o}} E\left[\left(\tilde{q}_{i j}-q_{i j}^{o}\right)^{3}\right]+E\left[R_{4}\right] \approx U\left(p q_{i j}^{o}-w\left(q_{i j}^{o}\right)\right)+\left.\frac{1}{2} \frac{\partial^{2} U}{\partial \tilde{q}_{i j}^{2}}\right|_{q_{i j}^{o}} \sigma^{2}+\left.\frac{1}{6} \frac{\partial^{3} U}{\partial \tilde{q}_{i j}^{3}}\right|_{q_{i j}^{o}} \kappa^{3}
\end{aligned}
$$

where $\sigma$ and $\kappa$ have been defined implicitly by the expected values they replace. Thus, rewriting,

$$
U\left(p q_{i j}^{o}-w\left(q_{i j}^{o}\right)\right) \approx E\left[U\left(p \tilde{q}_{i j}-w\left(\tilde{q}_{i j}\right)\right)\right]-\left.\frac{1}{2} \frac{\partial^{2} U}{\partial \tilde{q}_{i j}^{2}}\right|_{q_{i j}^{o}} \sigma^{2}-\left.\frac{1}{6} \frac{\partial^{3} U}{\partial \tilde{q}_{i j}^{3}}\right|_{q_{i j}^{o}} \kappa^{3} .
$$


To develop the left hand side of (4), start from a first order Taylor expansion ${ }^{3}$

$U\left(p \tilde{q}_{i j}-\tilde{w}\left(\tilde{q}_{i j}\right)\right)=U\left(p \tilde{q}_{i j}-w\left(\tilde{q}_{i j}\right)\right)+\left.\frac{\partial U}{\partial \tilde{w}\left(\tilde{q}_{i j}\right)}\right|_{w\left(\tilde{q}_{i j}\right)}\left(\tilde{w}\left(\tilde{q}_{i j}\right)-w\left(\tilde{q}_{i j}\right)\right)$

Taking the expectation, as in (4):

$E\left(U\left(p \tilde{q}_{i j}-\tilde{w}\left(\tilde{q}_{i j}\right)\right)\right)=E\left(U\left(p \tilde{q}_{i j}-w\left(\tilde{q}_{i j}\right)\right)\right)+E\left(\left.\frac{\partial U}{\partial \tilde{w}\left(\tilde{q}_{i j}\right)}\right|_{w\left(\tilde{q}_{i j}\right)}\left(\tilde{w}\left(\tilde{q}_{i j}\right)-w\left(\tilde{q}_{i j}\right)\right)\right)$

Equating RHS and LHS of (4), yields, after substituting (9) and (7),

$$
E\left(\left.\frac{\partial U}{\partial \widetilde{w}\left(\widetilde{q}_{i j}\right)}\right|_{w\left(\widetilde{q}_{i j}\right)} \widetilde{w}\left(\widetilde{q}_{i j}\right)\right)=E\left(\left.\frac{\partial U}{\partial \widetilde{w}\left(\widetilde{q}_{i j}\right)}\right|_{w\left(\widetilde{q}_{i j}\right)} w\left(\widetilde{q}_{i j}\right)\right)-\left(\left.\frac{1}{2} \frac{\partial^{2} U}{\partial \widetilde{q}_{i j}^{2}}\right|_{q_{i j}^{o}} \sigma^{2}+\left.\frac{1}{6} \frac{\partial^{3} U}{\partial \widetilde{q}_{i j}^{3}}\right|_{q_{i j}^{o}} \kappa^{3}\right)
$$

Since $w($.$) is determined on the labour market it is independent of the firm's utility and$ therefore we can write:

$$
E\left(\left.\frac{\partial U}{\partial \widetilde{w}\left(\widetilde{q}_{i j}\right)}\right|_{w\left(\widetilde{q}_{i j}\right)} \widetilde{w}\left(\widetilde{q}_{i j}\right)\right)=E\left(\left.\frac{\partial U}{\partial \widetilde{w}\left(\widetilde{q}_{i j}\right)}\right|_{w\left(\widetilde{q}_{i j}\right)}\right) E\left(w\left(\widetilde{q}_{i j}\right)\right)-\left(\left.\frac{1}{2} \frac{\partial^{2} U}{\partial \widetilde{q}_{i j}^{2}}\right|_{q_{i j}^{o}} \sigma^{2}+\left.\frac{1}{6} \frac{\partial^{3} U}{\partial \widetilde{q}_{i j}^{3}}\right|_{q_{i j}^{o}} \kappa^{3}\right)
$$

The expectation on the left hand side of $(11)$ is of the form: $E\left(\xi_{1} \xi_{2}\right)$ and is therefore equal to $\operatorname{cov}\left(\xi_{1}, \xi_{2}\right)+E\left(\xi_{1}\right) E\left(\xi_{2}\right)$ or:

$$
\begin{aligned}
& E\left(\left.\frac{\partial U}{\partial \widetilde{w}\left(\widetilde{q}_{i j}\right)}\right|_{w\left(\widetilde{q}_{i j}\right)}\right) E\left(\widetilde{w}\left(\widetilde{q}_{i j}\right)\right)= \\
& \quad E\left(\left.\frac{\partial U}{\partial \widetilde{w}\left(\widetilde{q}_{i j}\right)}\right|_{w\left(\widetilde{q}_{i j}\right)}\right) E\left(w\left(\widetilde{q}_{i j}\right)\right)-\left(\left.\frac{1}{2} \frac{\partial^{2} U}{\partial \widetilde{q}_{i j}^{2}}\right|_{q_{i j}^{o}} \sigma^{2}+\left.\frac{1}{6} \frac{\partial^{3} U}{\partial \widetilde{q}_{i j}^{3}}\right|_{q_{i j}^{o}} \kappa^{3}\right)-\operatorname{cov}\left(\left.\frac{\partial U}{\partial \widetilde{w}\left(\widetilde{q}_{i j}\right)}\right|_{w\left(\widetilde{q}_{i j}\right)}, \widetilde{w}\left(\widetilde{q}_{i j}\right)\right)
\end{aligned}
$$

Rearranging terms:

\footnotetext{
${ }^{3}$ We use here only a first order expansion as we now expand in the wage rather than in stochastic productivity.
} 


$$
\begin{array}{r}
E\left(\tilde{w}\left(\tilde{q}_{i j}\right)\right)=E\left(w\left(\tilde{q}_{i j}\right)\right)-\frac{1}{2} \frac{\partial^{2} U /\left.\partial \tilde{q}^{2}\right|_{q_{i j}}}{E\left(\partial U /\left.\partial \tilde{w}\left(\tilde{q}_{i j}\right)\right|_{w\left(\tilde{q}_{i j}\right)}\right.} \sigma^{2}-\frac{1}{6} \frac{\partial^{3} U /\left.\partial \tilde{q}^{3}\right|_{q_{i j}}}{E\left(\partial U /\left.\partial \tilde{w}\left(\tilde{q}_{i j}\right)\right|_{w\left(\tilde{q}_{i j}\right)}\right)} \kappa^{3} \\
-\frac{\operatorname{cov}\left(\left.\frac{\partial U}{\partial \tilde{w}\left(\tilde{q}_{i j}\right)}\right|_{w\left(\tilde{q}_{i j}\right)}, \tilde{w}\left(\tilde{q}_{i j}\right)\right)}{E\left(\partial U /\left.\partial \tilde{w}\left(\tilde{q}_{i j}\right)\right|_{w\left(\tilde{q}_{i j}\right)}\right)}
\end{array}
$$

So, we obtain the result that the wage offered by the firm deviates from what the market offers for expected productivity if this productivity were known by subtracting a premium to compensate for risk and skewness of unknown productivity. With second derivative of utility to productivity negative and third derivative positive, a higher variance reduces the offered wage and a higher skewness increases it, as the derivative to the wage is negative ${ }^{4}$.

Making the assumptions: $\widetilde{w}_{i j}=\widetilde{w}\left(\widetilde{q}_{i j}\right)=E\left(\widetilde{w}\left(\widetilde{q}_{i j}\right)\right)+\varepsilon_{i j}, E\left(\varepsilon_{i j}\right)=0$, and $E\left(w\left(\widetilde{q}_{i j}\right)\right)=\beta^{\prime} x_{i j}$, that the (fractions of the) derivatives with respect to utility can be approximated by constants, and that the last term can be considered purely random ${ }^{5}\left(\xi_{\mathrm{ij}}\right)$, we arrive at an estimable model:

$$
\widetilde{w}_{i j}=\beta^{\prime} x_{i j}+\alpha_{1} \sigma^{2}+\alpha_{2} \kappa^{3}+\left(\varepsilon_{i j}+\xi_{i j}\right)
$$

So far, we made the assumption that the effects of uncertainty about productivity are fully shifted to the worker. However, we may generalise this and assume that the incidence of risk is determined by relative bargaining power. To allow for risk sharing, we introduce a factor $0 \leq \theta_{j} \leq 1$ and rewrite the equilibrium condition as:

$$
\begin{aligned}
E\left[U\left(p \widetilde{q}_{i j}-\widetilde{w}\left(\widetilde{q}_{i j}\right)\right)\right] & =U\left(p q_{i j}^{o}-w\left(q_{i j}^{o}\right)\right) \\
& \approx E\left[U\left(p \widetilde{q}_{i j}-w\left(\widetilde{q}_{i j}\right)\right)\right]-\theta_{j}\left(\left.\frac{1}{2} \frac{\partial^{2} U}{\partial \widetilde{q}_{i j}^{2}}\right|_{q_{i j}^{o}} \sigma^{2}+\left.\frac{1}{6} \frac{\partial^{3} U}{\partial \widetilde{q}_{i j}^{3}}\right|_{q_{i j}^{o}} \kappa^{3}\right)
\end{aligned}
$$

\footnotetext{
${ }^{4}$ For the second derivative to be negative we need assume $\frac{\partial^{2} \Pi}{\partial q^{2}}<0$, which seems uncontroversial. The third derivative is positive if $\frac{\partial^{3} U}{\partial \Pi^{3}}$ is positive, a necessary condition for decreasing absolute risk aversion. ${ }^{5}$ Not necessarily with zero mean. A nonzero mean will be part of the constant in $\beta^{\prime} x_{i j}$
} 
If $\theta_{j}=1$, the employer is fully compensated by a lower wage, if $\theta_{j}=0$, the employer is not compensated at all. Going through the same steps as before, we end up with the following result:

$$
\widetilde{w}_{i j}=\beta^{\prime} x_{i j}+\alpha_{1} \theta_{j} \sigma^{2}+\alpha_{2} \theta_{j} \kappa^{3}+\varepsilon_{i j}+\xi_{i j}
$$

$\theta_{j}$ will depend on the market power of the firm relative to that of the worker. High unemployment or a higher level of concentration in the industry the firm operates in might cause $\theta_{j}$ to be closer to one. To model this assume:

$$
\theta_{j}=\frac{\exp \left(\gamma^{\prime} z_{j}\right)}{1+\exp \left(\gamma^{\prime} z_{j}\right)}
$$

where $z_{j}$ is a vector of variables representing the market power of firm $j$. With this specification we guarantee that $\theta_{j}$ is between 0 and 1 .

\subsection{Earlier literature}

Earlier literature has produced a few other models where imperfect information on worker abilities leads to a negative relationship between wages and the variance in the distribution of unobserved worker quality. None of these models have directly been put to an empirical test, however.

Rothschild and Stiglitz (1982) assume that productivity reacts negatively to mismatch, measured as deviation between imperfectly observable individual ability and the optimal ability level for a given job. Workers are assigned on the basis of expected ability, conditional on observed characteristics related to ability. Risk neutral employers pay wages equal to expected output. With a quadratic loss function for mismatches, expected output conditional on observable characteristics is negative in the variance of ability conditional on observables and so will be the wage.

Aigner and Cain (1977) assume that a skill indicator y measures true skill or productivity with error: $\mathrm{q}=\mathrm{y}+\mathrm{e}$. Employers maximize expected utility from profits, using a utility function with constant absolute risk aversion. This is equivalent to maximizing expected productivity conditional on y minus the variance of q conditional on $\mathrm{y}$. Adding the assumption of competition predicts wages to be positive in expected productivity and negative in productivity variance (both conditional on the indicator y):

$$
w=(1-\gamma) \bar{q}+\gamma y_{i}-\left(U^{\prime \prime} / U^{\prime}\right)(1-\gamma) \sigma_{q}^{2}
$$

where $\gamma$ is the squared correlation coefficient between y and $\mathrm{q}$ and where absolute risk aversion $U " / U$ ' is a constant. Hence, the wage reacts negatively to the variance of the indicator. 
Freeman (1977) introduced the idea that risk neutral firms are willing to insure starting workers against wage drops as information develops on their productivity. Harris and Holmstrom (1982) further developed this model to a market with risk neutral firms, risk averse workers and symmetric incomplete information on individual worker productivity. They show that wages are reduced by an insurance premium that diminishes with work experience (as information accumulates) and that is increasing in the (perceived) variance of productivity. Also, the variance of the wage increases with experience as wages come to reflect individual productivity. Harris and Holmstrom demonstrate that their model is in line with several stylized facts on wages, but offer no new direct testing.

Our model and the earlier models have in common that wages are predicted to fall with increasing (perceived) productivity risk of workers. Rothschild and Stiglitz essentially derive their conclusion from assumptions on the production function, while the other models focus on risk and insurance motives. Freeman and Harris-Holmstrom assume risk neutral firms selling insurance to risk neutral workers, while our model and Aigner and Cain assume risk averse firms that shift the cost of risk to workers. None of the earlier models considers the effects of asymmetry in the productivity distribution. To the best of our knowledge, there is no empirical work comparable to ours (see the overview in Waldman, 2007). Our paper is the first that directly tests the prediction that wages are lower if the variance in unobserved productivity is higher with an indicator of productivity variance.

\subsection{Measuring risk}

As employers cannot observe an applicant's productivity, we assume they will use the distribution of exam grades as an indicator of the extent of their uncertainty for a given type of education. The underlying notion is that there is some ability that determines both exam grades and productivity but in both cases with noise. Thus, knowing an individual's grade helps to predict ability and hence productivity, but not without errors. The variance of observed exam grades in a discipline reflects both measurement errors and unobserved heterogeneity. Our assumption on employers' use of the grade distribution to asses uncertainty in productivity essentially requires that an increase in unobserved heterogeneity does not lead to better predictability of individual productivity. We characterise this condition formally for a normal distribution; the normal distribution has no skewness, but if we assume a lognormal distribution the condition carries over to a case with skewness. We have no direct prior evidence on the validity of this condition. We have also been unable to come up with a tight formal specification of the required conditions in the general case of non-symmetric probability distributions. Non-symmetric distributions are needed to allow for a role of skewness; we do so because skewness has been shown to be empirically relevant in compensation to employees choosing a tye of education (Hartog, 2008; Hartog and Vijverberg, 2007). While we are unable to formulate an unambiguous prediction that grade variance has a negative and grade skewness has a positive effect on starting wages $^{6}$, we do find convincing empirical

\footnotetext{
${ }^{6}$ The problem emerges only in structural, causal modelling. If we reason from statistical relationships, the link is straightforward. Relating productivity q to ability a, $q=\beta a+\varepsilon$ and inferring ability from grade
} 
support for such a relationship. We take this as support for our interpretation, in particular as we see no convincing alternative model to explain the results.

For a formal analysis, let $\mathrm{g}_{\mathrm{i}}$ be the average grade of individual $\mathrm{i}$ upon graduating from tertiary education $\mathrm{s}$ (we only use data on tertiary graduates). Let $\mathrm{a}_{\mathrm{i}}$ be the unobserved ability of individual $i$ that determines both his average exam grade $g$ and his productivity $q$ in firm $\mathrm{j}$ :

$g_{i s}=\alpha_{s} a_{i}+\varepsilon_{i s}, \alpha_{s}>0$

$q_{i j s}=\beta_{j s} a_{i}+\varepsilon_{j}, \beta_{j s}>0$

$\varepsilon_{s i}$ and $\varepsilon_{j}$ are stochastic error terms, normally distributed with zero means and independent from ability $a$. Population variances are given by

$\sigma_{g s}^{2}=\alpha_{s}^{2} \sigma_{a}^{2}+\sigma_{i s}^{2}$

$\sigma_{q j}^{2}=\beta_{j s}^{2} \sigma_{a}^{2}+\sigma_{j}^{2}$

$V(q \mid g)$ is the variance of q conditional on $g$ (for convenience we suppress the subscript s):

$V(q \mid g)=\sigma_{q}^{2}\left(1-r^{2}\right)=\sigma_{q}^{2}\left(1-\frac{\sigma_{q g}^{2}}{\sigma_{q}^{2} \sigma_{g}^{2}}\right)$

where $\mathrm{r}^{2}$ is the squared correlation coefficient between $q$ and $g ; \sigma_{q g}^{2}$ is the covariance between grades $\mathrm{g}$ and productivity $\mathrm{q}$, or

$\sigma_{q g}^{2}=\alpha_{s} \beta_{j s} \sigma_{a}^{2}+\sigma_{i j}$

Where $\sigma_{i j}$ is the covariance between $\varepsilon_{i}$ and $\varepsilon_{j}$, which we assume to be zero.

Now suppose, $\sigma_{i}^{2}$ changes. Clearly, from (21) the effect on $\sigma_{g}^{2}$ is positive. For the effect on the conditional variance, we have

$$
\frac{\partial V}{\partial \sigma_{i}^{2}}=\left(1-r^{2}\right) \frac{\partial \sigma_{q}^{2}}{\partial \sigma_{i}^{2}}-\sigma_{q}^{2} \frac{\partial r^{2}}{\partial \sigma_{i}^{2}}
$$

$\mathrm{g}, a=\alpha g+v$ we have by substitution. $q=\beta \alpha g+\beta v+\varepsilon$. Moments of $\mathrm{g}$ are then linearly related to moments of q. 
where $\partial \sigma_{q}^{2} / \partial \sigma_{i}^{2}=0$. We have

$$
r^{2}=\frac{\alpha \beta \sigma_{a}^{2}}{\left(\alpha^{2} \sigma_{a}^{2}+\sigma_{i}^{2}\right)\left(\beta^{2} \sigma_{a}^{2}+\sigma_{j}^{2}\right)}
$$

which directly implies $\partial r^{2} / \partial \sigma_{i}^{2}<0$.

Thus, if $\sigma_{i}^{2}$ increases, both $\sigma_{g}^{2}$ and $V(q \mid g)$ increase, and increased grade variance signals increased productivity risk.

Now consider a change in $\sigma_{a}^{2}$. Then, clearly again from (21) the effect on $\sigma_{g}^{2}$ is positive. The effect on productivity risk equals

$$
\begin{aligned}
\frac{\partial V}{\partial \sigma_{a}^{2}} & =\left(1-r^{2}\right) \frac{\partial \sigma_{q}^{2}}{\partial \sigma_{a}^{2}}-\sigma_{q}^{2} \frac{\partial r^{2}}{\partial \sigma_{a}^{2}} \\
& =\left(1-r^{2}\right) \beta^{2}-\left(\beta^{2} \sigma_{a}^{2}+\sigma_{j}^{2}\right) \frac{\partial r^{2}}{\partial \sigma_{a}^{2}}
\end{aligned}
$$

Since we can write

$$
r^{2}=\frac{\alpha \beta}{\left(\alpha^{2}+\frac{\sigma_{i}^{2}}{\sigma_{a}^{2}}\right)\left(\beta^{2}+\frac{\sigma_{j}^{2}}{\sigma_{a}^{2}}\right)}
$$

it is clear that the effect of $\sigma_{a}^{2}$ on $r^{2}$ is positive and hence, that (28) cannot be signed without parameter restrictions.

We can express the condition for (27) to be positive in terms of underlying parameter values, but such a condition is not particularly illuminating. But if we define $E(r, a)$ as the elasticity of the correlation coefficient $r^{2}$ with respect to ability variance and $E(q, a)$ as the elasticity of productivity $q$ with respect to ability variance, we get a condition that does have intuitive appeal. The derivative in (27) will be positive if ${ }^{7}$

\footnotetext{
${ }^{7}$ This follows directly from differentiating (23) to $\sigma_{a}^{2}$ and rewriting in terms of elasticities.
} 


$$
\frac{E(r, a)}{E(q, a)}<\frac{\left(1-r^{2}\right)}{r^{2}}
$$

This indicates an upper limit on the ratio of the two elasticities: in that sense the effect of increased ability variance on the correlation coefficient should be small relative to the effect on productivity variance. If condition (30) holds we can say that an observed increased variance in exam grades implies an increased variance in productivity, no matter whether the increased variance in grades is due to increased heterogeneity or increased noise.

The argument above extends directly to skewness if we assume lognormal distributions. The conditions developed above then apply to the variances of the logs, and with variance and skewness of the variables themselves monotonic transformations of the log variance, the conclusions carry over to the case of positively skewed log normal distributions.

\section{Data}

We use data from the Elsevier/SEO survey, held among graduates from tertiary education. A new cohort of graduates has been interviewed every year since 1996, with focus on outcomes in the first 20 months in the labour market. Dutch tertiary education is basically divided into two levels: higher vocational education (in Dutch abbreviated as HBO) and university education (WO). HBO-education prepares students for specific (categories of) professions. It is taught at about 60 special institutes evenly spread over the Netherlands. On average, 50,000 students graduate each year from HBO. WO-education is considered to be of a somewhat higher intellectual level and has a more general academic character; it also requires a higher level of secondary education for direct admission. It is taught at 14 universities. Approximately 23,000 students graduate every year. At HBO-level students can choose between 250 different courses of study, while at WO-level they may choose between 260 different specializations. Most of them, however, produce only small numbers of graduates, making statistical analysis based on variances in grades within specialisations unreliable. About 80 percent of the student population is concentrated in the 113 largest degree fields. The survey is restricted to these 113 degree fields (studies) which divide evenly over HBO and WO. This means the survey is representative of 80 percent of the yearly outflow of graduates at HBO- and WO-level. Every year a sample of on average 7,500 observations is drawn. The special feature of the survey is the large number of studies within tertiary education and the focus on starting salaries

We pool 9 cohorts, from 1999 until 2007, with a time dummy to distinguish them. Earnings are defined as log net hourly wages at the time of the survey, i.e. on average 20 months after graduation (reported earnings are divided by reported hours); salaries are self-reported and may contain the associated noise. For our empirical purposes, we excluded all respondents who are self-employed, part time employed (less than 32 hours a week) and all those for whom data on control variables are unavailable. To eliminate outliers, we discarded both the 
highest and the lowest $1 \%$ of the sample. All correlations between explanatory variables are low, and we need not worry about multicolinearity. The data, based on about 45000 observations from 113 schooling types, are characterised in the Appendix.

To estimate our model and test the predictions, we need observations on expected productivity, in particular variance and skewness. In the Elsevier/SEO data individuals were asked for their average exam grade, across courses, in tertiary education (grading uses a standard 0-10 scale; passing requires a minimum of 5.5, though not necessarily for all courses, as compensation is sometimes allowed). As explained in section 2.3, we take the dispersion (and skewness) of exam grades, for all students with a given type of tertiary education, as an indication of dispersion (and skewness) of the productivity distribution.

The dataset allows us to use many variables, i.e. to control for the situation in the labour market (region, unemployment/vacancy ratio, time in the labour market since graduation), personal characteristics (age, gender, parents' education, individual grades) and job characteristics (job level, industry, type of contract). These variables should be sufficient to predict expected productivity. We also control for the workers' risk when selecting an education, by including variance and skewness of the earnings residual in the chosen education. The argument here is that potential students will only select an education if they are compensated for the earnings risk of that education. Formal modelling and a survey of empirical results are given in Hartog (2008), examples in Hartog and Vijverberg (2007) and Diaz Serrano, Hartog and Skyt Nielsen (2008). Risk is measured as the variance of the residuals from a Mincer earnings function within that education ${ }^{8}$. We will not elaborate on wage compensation for the workers' risk when choosing an education but only note that compensation for employer risk and employee risk neatly mirror each other, as theory predicts. Workers demand and get compensation for risk and are willing to take a pay reduction for a better chance of very high incomes and hence accept lower wages for higher skewness?.

Mean wages are plotted against variance and skewness of exam grades in Figure 1. The plots indicate weak correlations (negative and positive, respectively) ${ }^{10}$ The data indicate no obvious patterns of structural relations between the variables that might be reason for suspicion. Some of the studies that are intellectually more demanding (like biomedical science and pure mathematics) have high variance, but among the high variance fields we also find less demanding fields, like sociology and languages. A field with restrictive entry like medicine has grade variance in the higher end of the distribution but a similar field like dentistry has low variance.

\section{Basic results}

\footnotetext{
${ }^{8}$ In Hartog (2008) we extensively discuss the selectivity problem and the potential ability bias when using residual variance as a measure of risk.

${ }^{9}$ Full analysis of worker risk compensation in the present dataset, with formal modelling and references is given in Berkhout, Hartog and Webbink (2006).

${ }^{10}$ The remarkable outlier is dentistry; we have no explanation.
} 
Tables 1, 2 and 3 give the basic results. As announced, we include the results on worker risk, as they give a strong background to the compensation for employer risk. Worker risk is measured by the residual earnings variance within an education type from a Mincer equation across all educations: a positive effect for the variance (Erisk) as workers do not like risk, a negative effect for skewness (Eskew), as workers like positive asymmetry (with some extra probability of a very high outcome). Estimation results for Erisk and Eskeware robust in magnitude and statistical significance (except for some variation across industries) and will not be commented on in detail. With education completed, workers have no alternative and employers can shift the risk from the heterogeneity they cannot observe to workers, as we argued in section 2. The results we report here on employer's risk are independent of employee's risk: regression coefficients vary only marginally and significance levels are unaffected when employee risk is excluded or included. We take the robust mirroring of employer risk compensation in employee risk compensation, in line with the distinction between ex ante elastic and ex post perfectly inelastic choice of education as strong support for our approach.

We start, in Table 1, with an OLS estimation at the level of studies, with the mean earnings in a field of study as the dependent variable. Our basic prediction is strongly supported: in studies with higher variance in grades, starting salaries are lower, with higher skewness in grades they are higher. The results are not sensitive to including or excluding compensation for worker risk.

In Table 2 we present estimates with individual earnings as the dependent variable and standard errors adjusted for clustering, as there may be correlation for errors within fields of education, the so-called Moulton problem. Selection of variables for which clustering is allowed is by no means obvious and there exist as yet no statistical tests to guide this process. For almost any independent variable one might claim similar or correlated shocks for subsets (males versus females, regions, occupations, ability classes) and one should make an a priori choice based in part on practical considerations. We allow for clustering by education type, as we measure our independent variables of prime interest by type of education ${ }^{11}$.

Again, the basic prediction is supported, with similar coefficients, but sometimes lower precision. The advantage of the estimation on micro data is the possibility to include additional controls for other variables that influence earnings. As Table 2 shows, in panel A, the coefficients are sensitive to controls for personal and job characteristics but not for time and region. Precision also falls and significance levels become low. This suggests that some of the variation in earnings initially ascribed to risk as reflected in dispersion in school grades is due to heterogeneity among individuals and their jobs. Note that risk is not recalculated when we add controls and this must imply that school grade heterogeneity is correlated with the controls we use.

${ }^{11}$ We experimented with different types of education clustering, based on our a priori notions on related shocks arising from sensitivity to related product or labour markets (e.g clustering all language educations). Reducing the number of clusters by assumed market similarities proved immaterial for the results. 
In Table 3, we present estimates for a random effects model. Random effects at the level of the studies control for unobserved variables that explain differences in earnings and that may bias the estimates of our risk coefficients. As the first column of panel A shows, the coefficients for grade variance and skew do not change much, but statistical significance increases ${ }^{12}$. Adding controls now has far less effect than in Table 2. The reduction in magnitude of the coefficients is smaller and they remain significant at conventional level. Thus controlling for unobserved heterogeneity between the studies increases support for our hypothesis.

Finally, we note that the effect of individual school grades is quite small. School performance is graded on a $0-10$ scale, with 6 or more required for a pass. In the OLS model, a one unit grade point difference in average exam score increases starting wages by about 1 percent. Overall, the standard deviation of individual grades is about 0.5 . Thus, a one standard deviation increase in individual grades raises starting wage by 0.5 percent. In the RE model, particularly when combined with clustered standard errors, the effect of individual school grades is neither statistically significant nor substantial (except in one case).

\section{Robustness and economic magnitudes}

As a check on the robustness of our results, we have considered some alternative explanations for our results. One explanation is based on differences in intellectual requirements between fields of study: some studies can only be completed for students with high analytical ability. This will generate self-selection at entry ${ }^{13}$ and selective dropout based on those requirements. In the end, the population of graduates may be rather homogenous. As these high ability graduates may also be expected to obtain high earnings, we would see a negative correlation between earnings and grade variance. With truncation at the low end of the ability distribution, a positive correlation between earnings and grade skew would also result. The problem is of course to measure the differences in intellectual requirements (or "difficulty") of studies. We considered applying a distinction based on our own perceptions but discarded this as too subjective. Instead we based the distinction on the grade points. We selected students in the middle of the ability distribution as indexed by grades for the final exam of secondary school: only students close to the overall mean exam grade are retained (we used the middle third of the distribution, symmetrically about the median). In addition, we required the variance in the individual's exam grades across subjects to be small (we used the middle third of the distribution). Thus, we have a fairly homogeneous group of students, about $9 \%$ of the sample. We then calculated the differences between their mean exam grades and the mean exam grade in their tertiary study. Based on these differences we split studies between "difficult" and "easy", as two roughly equally large groups. The difficult studies have the larger average gap between tertiary grade and secondary grade. Although

${ }^{12}$ If we calculate the standard errors in the random effects model without clustering, $t$-values are not below 2.4 .

${ }^{13}$ Dutch universities do not select at entry, anyone with the proper secondary school diploma must be admitted. In higher vocational education, schools may restrict entry. 
the resulting distinction does not always match our own perceptions, we used this distinction to add a dummy for difficult studies to our estimation equation. As Tables 2 and 3 (panels B) show, the coefficient on this dummy is not statistically significant and inclusion has no effect on any of the other coefficients. In fact, observing the variance of grades by type of educations also provides evidence against this explanation. As we noted at the end of section 3, intellectually demanding studies do not stand out with low grade variance: among vocational graduates, variance is high for medical imaging and radiotherapy, applied informatics and applied physics, among university graduates it is high for chemistry, computer science, biology, pure mathematics, electrical engineering, econometrics and biomedical science.

Another potential explanation is based on the organisation of the studies and on labour market structure. Some studies are rather strictly organized, with attendance requirements (e.g. in laboratories), regular assignments and active student monitoring. This may increase the homogeneity of the population of graduates, with low grade variance as a result. The effect on grade skewness is less clear. If these happen to be the studies leading to high paid jobs, there would be a negative correlation between earnings and grade variance. Medicine would be an example. In some occupational fields government regulations lead to a monopolistic market structure. In such occupations, earnings are high. If such a monopoly coincides with strict organization and student monitoring, again as in medicine, this would also generate the negative correlation between earnings level and grade variance. To check this argument, we added a dummy for 7 studies preparing for a job in a highly regulated market: physiotherapy, medical techniques and radiotherapy, dental hygiene, pharmacy, notary, medicine, dentistry. All the medical studies are strictly organised and regulated, notary is regulated but the study is not strictly organised. The dummy has the expected positive effect on earnings, but inclusion has no effect on any other coefficient (Tables 2 and 3, second panel).

We also considered, in Table 4, the effects within subpopulations, with variance and skewness calculated for the relevant sub-populations. We only present RE estimates, as we believe that allowing for unobserved heterogeneity among educations is indeed called for (as above, OLS estimates have higher standard errors). Statistical precision falls, in particular for grade skewness. Some wrong signs occur, but we never find significant violation of the hypothesis in the form of a wrong sign that is statistically significant. Separate estimation for men and women does not affect the results. If we allow the labour market to be segmented by "ability", we find robust results for grade variance but insignificance for grade skewness. We have created ability quartiles on the basis of average grade in the secondary school final exam (quartile 1 is the lowest grade segment). School grades are influenced by ability and drive and both are relevant to employers. Our results suggest that the effect of risk is not driven by a spurious effect of ability/ambition as reflected in school grades. Distinction by time between graduation and time of survey (work experience longer or shorter than the mean) does not affect the results. Distinction between difficult and easy studies again produces no violation of the basic predictions ${ }^{14}$. Separate estimation for six employment sectors produces no

\footnotetext{
${ }^{14}$ We also checked the effect of deleting any cohort $t$, for $\mathrm{t}=1$ to 11 from the sample; this proved immaterial for the estimation results.
} 
significant violations; results are significantly confirmed for three sectors (Government, Services and Manufacturing), but insignificant for Education and Care. Education and Care are industries with excess demand, so this might reflect a disequilibrium result. However, separating the vocational educations in Education and Care from the other industries did not improve results.

If we distinguish between university and higher vocational education, the results within these subgroups are no longer statistically significant. This seems to suggest that our results are determined by the distinction between these two types of educations rather than by market operation within the segments. This does not harm our prediction in any essential way, as it explains differences between university and vocational education from the risk properties in their labour markets.

We can express the magnitude of the effects in elasticities, by multiplying the coefficients by the mean of the independent variable. Table 5 collects results. It's immediately clear that all elasticities are small and not very sensitive to specification. The wage elasticity for grade variance is between 0.05 and 0.10 , the wage elasticity for grade skew is between 0.01 and 0.02 . The variance of these elasticities within subgroups is modest. Mean values of grade variance and grade skew vary remarkably little between the subgroups, and hence the estimated regression coefficients give a good indication of the variation. The wage differential between the education with maximum and minimum grade variance is $10 \%$ (the variances are 0.455 and 0.137 ), between education with maximum and minimum grade skew is $6.5 \%$ (the skew is .244 and -.013 ; we use the regression coefficients in column A4, Table 3). Thus, the effect on wage differentials is not negligible.

\section{Risk sharing}

As noted in section 2, we can allow for risk cost sharing between worker and firm, rather than impose that the worker will bear the full burden. In (16), we allow for a sharing parameter $\theta$ that is made to depend on parameters that affect relative bargaining power. $\theta$ is a parameter between 0 and 1 , where the value of 1 indicates that the employer is fully compensated for productivity risk with a lower wage and the value 0 indicates that the employer fully carries the cost of risk without any compensation in wages. Equation (17) specifies a regression equation for $\theta$ as a logit model. In particular, we estimated the following model

$$
\begin{aligned}
& L n w_{i j}=\beta^{\prime} x_{i j}+\theta_{j}\left(\delta_{1} \sigma_{j}^{2}+\delta_{2} \kappa_{j}^{3}\right)+\varepsilon_{i j} \\
& \theta_{i}=\frac{\exp Z_{i} \alpha}{1+\exp Z_{i} \alpha}
\end{aligned}
$$

Results are given in Table 6. We have experimented a little with assigning variables to the linear part of the wage equation and the non-linear part through the risk sharing 
parameter $\theta$. Due to high levels of multicolinearity, we could not have all variables in both the linear and the non-linear part. Estimated coefficients on the linear part of the wage equation are not much different from our earlier estimates. Grade variance and grade skewness come out with the right signs, and have even higher significance levels than before. Base values are lower in absolute sense, but now are no longer constant. In the risk cost sharing part, a positive coefficient indicates that the variable contributes to shifting the cost of risk to the worker, by reducing the wage rate for a given risk. Thus, graduates from vocational education have larger wage reduction for given risk than university graduates. In the private sector, wages are more reduced for given employer risk than in the public sector: with the government as reference sector, and education and health care as mostly public sectors, the private sectors all have higher coefficients. Business services mostly shift the cost of risk to workers, the education sector shifts least. Interestingly, as shown in Figure 2, the year dummies trace the profile of the national unemployment rate. If unemployment goes up, the year dummy goes up, indicating that with higher unemployment, the worker has to pay a higher share of the risk.

Our model in section 2 makes a distinction between starting workers and experienced workers, with extreme assumptions on information about their productivity: jumping from no individual information to full information. In practice, of course, information develops gradually, as eg in Harris and Holmstrom (1982). We can use these models to predict that gradually, as information on individual productivity develops, workers will have to pay less to compensate employers' risk: $\theta$ should decline with experience. This is indeed exactly what we find. In the linear model (as reported in Table 3), we have split the sample in two groups: work experience since graduation less than 18 months or greater than 18 months. For the total sample we estimated $\theta$ of 0.317 (standard error 0.076). For the short experience sample, with 19634 observations, we find 0.307 (0.052), for the more experienced sample (25 340 observations) we find 0.243 (0.040). We have also estimated a continuous specification, with experience since graduation in months $\mathrm{m}$. A parabolic specification in the $\theta$ logit yields $0.027 \mathrm{~m}-0.0016 \mathrm{~m}^{2}$; only the quadatric term is statistically significant ${ }^{15}$. The parabola peaks at 8.4 months and is negative after 16.9 months. Clearly, the price that workers pay for the uncertainty that employers face when hiring them falls over time.

\section{Conclusion}

From an analytical model, we derived the prediction that firms would pay lower starting wages if they face larger variance in individual productivity and higher wages if they have more favourable odds of hiring individuals with very high productivity. The model formalises the argument that firms shift the risk associated with uncertain productivity of labour market entrants to the worker, but are willing to pay for the probability of hitting upon exceptionally good workers. The prediction on the effect of the variance is similar to that in Harris and Holmstrom (1982), the prediction on skew is derived only in our own model.

\footnotetext{
${ }^{15}$ With a simple linear specification, estimated coefficients are statistically not significant.
} 
We use the distribution of exam grades to obtain information on the distribution of individual productivity for given education. We find that starting wages are lower if the variance of individual qualities increases and that the starting wage increases if the skew in individual qualities increases. These results are robust within sub-populations and also survive some tests against alternative interpretations. The results are stronger if we estimate a random effects model than when we apply OLS. This strengthens our case, as the RE model controls for unobserved heterogeneity among educations. In a non-linear specification we have estimated the extent of risk cost sharing between employers and workers. We find that vocational graduates pay more for the productivity risk that employers face than university graduates and that employers in the market sector shift a larger share to workers than public sector employers. As experience grows, workers pay less for employers productivity risk. We have estimated standard errors with allowance for clustering of educations, but actually we find clustering a rather arbitrary procedure, as it is unclear a priori what clustering structure is called for and ex post one cannot test for statistical significance. Dropping clustering would decrease our standard errors and increase statistical significance considerably.

In all specifications, we include worker's financial risk, as reflected in the distribution of residuals within an education. In all specifications, we find a positive effect of residual variance and a negative effect of residual skewness. We also take this as (circumstantial) evidence for our approach as it indicates general support for the notion that risk has an effect on wages. In fact we find opposing results neatly in line with economic theory. As individuals ex ante have a choice in the education they will pursue, they will shift financial risk to employers. But with their education completed, they have no alternative and employers shift productivity risk to employees.

Our analytical model did not yield unambiguous results. The negative effect of variance and the positive effect of skewness can only be predicted if certain (parameter) conditions hold. Our empirical results are unambiguous however. As we see no obvious alternative explanation, we take the empirical results as clear support for our interpretation: employers shift part of the cost of productivity risk to workers. 


\section{References}

Aigner, D. and G. Cain (1977), Statistical theories of discrimination in labor markets, Industrial and Labor Relations Review, 30 (5), 175- 187

Altonji, J. and C. Pierret (2001), Employer learning and statistical discrimination, Quarterly Journal of Economics, 116 (1), 313-350

Berkhout, P., J. Hartog and D. Webbink (2006), Risk compensation under worker heterogeneity, Bonn: IZA Discussion Paper 2074, (forthcoming in Southern Economic Journal, January 2010)

Diaz Serrano, L., J. Hartog and H. Skyt Nielsen (2008), Compensating Wage Differentials for Schooling Risk in Denmark, Scandinavian Journal of Economics, 110 (4), 711-731,

Farber, H. and R. Gibbons (1996), Learning and wage dynamics, Quarterly Journal of Economics, 111 (4), 1007-1047

Freeman, S. (1977), Wage Trends as Performance Displays Productive Potential: A Model and Application to Academic Early Retirement, Bell Journal of Economics, 8, 419-443.

Harris, M. and B. Holmstrom (1982), A theory of wage dynamics, Review of Economic Studies, 49 (3), 315-333

Hartog, J. (2008), A Risk Augmented Mincer Earnings equation? Taking stock, Working Paper University of Amsterdam

Hartog, J. and W. Vijverberg (2007), On compensation for risk aversion and skewness affection in wages Labour Economics, Special Issue on Education and Risk, 14 (6), 938-956

NRC Handelsblad (2006), Philips verkoopt chips divisie, August 4, 2006

Rothschild, M and J. Stiglitz (1982), A model of employment outcomes illustrating the effect of the structure of information on the level and distribution of income, Economics Letters, 10, 231-236

Waldman, M. (2007), Theory and evidence in internal labor markets, MPRA Paper 5113, online at http://mpra.ub.uni-muenchen.de/5113/ 
Table 1. OLS on aggregate data (113 studies)

\begin{tabular}{|l|r|r|}
\hline Ln hourly wage & Coef. & t-val \\
\hline Intercept & 2.225 & 59.04 \\
Erisk & 3.054 & 5.27 \\
Eskew & -2.992 & -3.04 \\
Grade variance & -0.422 & -2.61 \\
Grade skew & 0.442 & 2.58 \\
\hline
\end{tabular}

$\mathrm{N}=113, \mathrm{R}^{2}=0.249$ 
Table 2. OLS on micro data

\begin{tabular}{|c|c|c|c|c|c|c|c|c|}
\hline & \multicolumn{8}{|c|}{ Regressions } \\
\hline $\begin{array}{l}\text { Ln hourly } \\
\text { wage }\end{array}$ & A1 & A2 & A3 & A4 & B1 & B2 & B3 & B4 \\
\hline $\begin{array}{l}\text { Erisk } \\
\quad(\mathrm{t}-\mathrm{val})\end{array}$ & $\begin{array}{l}3.512 \\
(3.12)\end{array}$ & $\begin{array}{l}3.428 \\
(3.05)\end{array}$ & $\begin{array}{l}2.888 \\
(2.45)\end{array}$ & $\begin{array}{r}2.801 \\
(5.55)\end{array}$ & $\begin{array}{l}3.288 \\
(3.21)\end{array}$ & $\begin{array}{l}3.214 \\
(3.13)\end{array}$ & $\begin{array}{l}2.774 \\
(2.52)\end{array}$ & $\begin{array}{r}2.757 \\
(5.24)\end{array}$ \\
\hline Eskew (t-val) & $\begin{array}{r}-3.454 \\
(- \\
1.78)\end{array}$ & $\begin{array}{r}-3.342 \\
(- \\
1.72)\end{array}$ & $\begin{array}{r}-2.721 \\
(- \\
1.46)\end{array}$ & $\begin{array}{r}-2.898 \\
(-10)\end{array}$ & $\begin{array}{r}-3.021 \\
(- \\
1.88)\end{array}$ & $\begin{array}{r}-2.932 \\
(- \\
1.82)\end{array}$ & $\begin{array}{r}-2.469 \\
(- \\
1.50)\end{array}$ & $\begin{array}{r}-2.702 \\
(- \\
3.80)\end{array}$ \\
\hline $\begin{array}{r}\text { Grade variance } \\
\qquad(\mathrm{t}-\mathrm{val})\end{array}$ & $\begin{array}{r}-0.504 \\
(- \\
2.09)\end{array}$ & $\begin{array}{r}-0.471 \\
(- \\
1.98)\end{array}$ & $\begin{array}{r}-0.349 \\
(- \\
1.54)\end{array}$ & $\begin{array}{r}-0.223 \\
(- \\
2.36)\end{array}$ & $\begin{array}{r}-0.534 \\
(- \\
2.40)\end{array}$ & $\begin{array}{r}-0.500 \\
(- \\
2.30)\end{array}$ & $\begin{array}{r}-0.399 \\
(1.96)\end{array}$ & $\begin{array}{r}-0.224 \\
(- \\
2.50)\end{array}$ \\
\hline $\begin{array}{l}\text { Grade skew } \\
\text { (t-val) }\end{array}$ & $\begin{array}{r}0.495 \\
(1.97)\end{array}$ & $\begin{array}{r}0.439 \\
(1.80)\end{array}$ & $\begin{array}{l}0.231 \\
(1.03)\end{array}$ & $\begin{array}{r}0.118 \\
(1.33)\end{array}$ & $\begin{array}{r}0.508 \\
(2.12)\end{array}$ & $\begin{array}{l}0.453 \\
(1.96)\end{array}$ & $\begin{array}{r}0.268 \\
(1.27)\end{array}$ & $\begin{array}{r}0.102 \\
(1.15)\end{array}$ \\
\hline $\begin{array}{l}\text { Individual } \\
\text { grades }\end{array}$ & 0.017 & 0.015 & 0.019 & 0.010 & 0.012 & 0.011 & 0.015 & 0.009 \\
\hline (t-val) & (3.93) & $(3.40)$ & $(4.58)$ & $(3.41)$ & (3.24) & $(2.71)$ & (3.74) & (3.16) \\
\hline $\begin{array}{l}\text { Difficult } \\
\qquad(\mathrm{t}-\mathrm{val})\end{array}$ & & & & & $\begin{array}{r}-0.014 \\
(- \\
0.87)\end{array}$ & $\begin{array}{r}-0.014 \\
(- \\
0.89)\end{array}$ & $\begin{array}{r}-0.019 \\
(- \\
131)\end{array}$ & $\begin{array}{r}-0.000 \\
(- \\
0.01)\end{array}$ \\
\hline $\begin{array}{l}\text { Regulated } \\
\qquad(\mathrm{t}-\mathrm{val})\end{array}$ & & & & & $\begin{array}{r}0.094 \\
(1.63)\end{array}$ & $\begin{array}{r}0.093 \\
(1.67)\end{array}$ & $\begin{array}{r}0.079 \\
(1.81)\end{array}$ & $\begin{array}{l}0.031 \\
(1.66)\end{array}$ \\
\hline $\mathrm{R}^{2}$ & 0.033 & 0.061 & 0.081 & 0.203 & 0.046 & 0.073 & 0.090 & 0.204 \\
\hline
\end{tabular}

$\mathrm{N}=44974$; $\mathrm{t}$-values based in standard errors clustered by field of education.

$A=$ Regression without dummies for difficult and regulated studies.

$\mathrm{B}=$ Regression with dummies for difficult and regulated studies.

$1=$ intercept only.

$2=$ as 1 , plus labour market variables (year dummies, regions, time since graduation).

$3=$ as 2 , plus personal characteristics (age, gender, parental education).

$4=$ as 3 , plus job characteristics (job level, industry, contract type).

Difficult = dummy for difficult studies (see text).

Regulated $=$ dummy for regulated studies (see text). 
Table 3 Estimation with random effects on micro data

\begin{tabular}{|c|c|c|c|c|c|c|c|c|}
\hline & \multicolumn{8}{|c|}{ Regressions } \\
\hline $\begin{array}{l}\text { Ln hourly } \\
\text { wage }\end{array}$ & A1 & A2 & A3 & A4 & B1 & B2 & B3 & B4 \\
\hline $\begin{array}{l}\text { Erisk } \quad(\mathrm{t}-\mathrm{val}) \\
\end{array}$ & $\begin{array}{r}3.741 \\
(5.44)\end{array}$ & $\begin{array}{r}3.681 \\
(5.71)\end{array}$ & $\begin{array}{r}3.548 \\
(5.48)\end{array}$ & $\begin{array}{r}2.978 \\
(6.36)\end{array}$ & $\begin{array}{r}3.092 \\
(5.88)\end{array}$ & $\begin{array}{l}3.065 \\
(6.22)\end{array}$ & $\begin{array}{r}2.979 \\
(6.05)\end{array}$ & $\begin{array}{l}2.718 \\
(7.23)\end{array}$ \\
\hline Eskew (t-val) & $\begin{array}{r}-3.656 \\
(-\end{array}$ & $\begin{array}{r}-3.556 \\
(-\end{array}$ & $\begin{array}{r}-3.496 \\
(-\end{array}$ & $\begin{array}{r}-2.709 \\
(-\end{array}$ & $\begin{array}{r}-2.649 \\
(-\end{array}$ & $\begin{array}{r}-2.596 \\
(-\end{array}$ & $\begin{array}{r}-2.605 \\
(-\end{array}$ & $\begin{array}{r}-2.269 \\
(-\end{array}$ \\
\hline Grade & $\begin{array}{r}3.45) \\
-0.546\end{array}$ & $\begin{array}{r}3.43) \\
-0.542\end{array}$ & $\begin{array}{r}3.43) \\
-0.506\end{array}$ & $\begin{array}{r}3.78) \\
-0.336\end{array}$ & $\begin{array}{r}3.22) \\
-0.516\end{array}$ & $\begin{array}{r}3.15) \\
-0.512\end{array}$ & $\begin{array}{r}3.24) \\
-0.480\end{array}$ & $\begin{array}{r}3.67) \\
-0.324\end{array}$ \\
\hline$(\mathrm{t}-\mathrm{val})$ & (- & (- & & & & & $\begin{array}{r}(- \\
3.42)\end{array}$ & \\
\hline $\begin{array}{l}\text { Grade skew } \\
\text { (t-val) }\end{array}$ & $\begin{array}{r}0.495 \\
(2.18)\end{array}$ & $\begin{array}{r}0.459 \\
(2.07)\end{array}$ & $\begin{array}{r}0.377 \\
(1.88)\end{array}$ & $\begin{array}{r}0.256 \\
(2.03)\end{array}$ & $\begin{array}{r}0.423 \\
(2.05)\end{array}$ & $\begin{array}{r}0.390 \\
(1.93)\end{array}$ & $\begin{array}{r}0.312 \\
(174)\end{array}$ & 0.232 \\
\hline $\begin{array}{l}\text { Individual } \\
\text { grades }\end{array}$ & 0.002 & 0.000 & 0.005 & 0.011 & 0.002 & 0.000 & 0.005 & 0.011 \\
\hline (t-val) & $(0.74)$ & $(0.08)$ & $(1.67)$ & (4.62) & $(0.73)$ & $(0.06)$ & (1.65) & $(4.54)$ \\
\hline $\begin{array}{l}\text { Difficult } \\
\text { (t-val) }\end{array}$ & & & & & & & $\begin{array}{r}-0.015 \\
(-\end{array}$ & $\begin{array}{r}-0.005 \\
(-\end{array}$ \\
\hline & & & & & $1.29)$ & $1.25)$ & $1.32)$ & $0.63)$ \\
\hline $\begin{array}{l}\text { Regulated } \\
\text { (t-val) }\end{array}$ & & & & & $\begin{array}{r}0.119 \\
(2.97)\end{array}$ & $\begin{array}{r}0.113 \\
(3.01)\end{array}$ & $\begin{array}{r}0.104 \\
(3.34)\end{array}$ & $\begin{array}{l}0.054 \\
(2.51)\end{array}$ \\
\hline St de & 0.069 & 0.061 & 0.056 & 0.024 & 0.066 & 0.060 & 0.056 & 0.024 \\
\hline & 0.202 & 0.199 & 0.198 & 0.18 & 0.202 & 0.199 & 0.198 & 0.188 \\
\hline $\mathrm{R}^{2}$-within & 0.000 & 0.028 & 0.038 & 0.139 & 0.000 & 0.028 & 0.038 & 0.140 \\
\hline $\mathrm{R}^{2}$-between & 0.376 & 0.414 & 0.486 & 0.772 & 0.459 & 0.488 & 0.551 & 0.782 \\
\hline $\mathrm{R}^{2}$-overall & 0.047 & 0.076 & 0.096 & 0.223 & 0.056 & 0.085 & 0.103 & 0.225 \\
\hline
\end{tabular}

$\mathrm{N}=44974$, t-values based in standard errors clustered by field of education.

$\mathrm{A}=$ Regression without dummies for difficult and regulated studies.

$\mathrm{B}=$ Regression with dummies for difficult and regulated studies.

$1=$ intercept only.

$2=$ as 1 , plus labour market variables (year dummies, regions, time since graduation).

$3=$ as 2 , plus personal characteristics (age, gender, parental education).

$4=$ as 3 , plus job characteristics (job level, industry, contract type.)

Difficult = dummy for difficult studies (see text).

Regulated $=$ dummy for regulated studies (see text). 
Table 4 Random effects estimation on micro data, subpopulations

\begin{tabular}{|c|c|c|c|c|c|c|c|}
\hline Ln hourly wage & Erisk & Eskew & $\begin{array}{l}\text { Grade } \\
\text { var. }\end{array}$ & $\begin{array}{l}\text { Grade } \\
\text { skew }\end{array}$ & $\begin{array}{l}\text { Ind. } \\
\text { grades }\end{array}$ & $\begin{array}{l}\mathbf{R}^{2} \\
\text { (overall) }\end{array}$ & $\mathbf{N}$ \\
\hline$(\mathrm{t}-\mathrm{val})$ & $\begin{array}{l}2.978 \\
(6.64)\end{array}$ & $\begin{array}{l}-2.709 \\
(-3.78)\end{array}$ & $\begin{array}{l}-0.336 \\
(-3.30)\end{array}$ & $\begin{array}{l}0.256 \\
(2.03)\end{array}$ & $\begin{array}{r}0.011 \\
(4.62)\end{array}$ & 0.223 & 44974 \\
\hline University & $\begin{array}{l}2.895 \\
(5.91)\end{array}$ & $\begin{array}{l}-2.933 \\
(-3.98)\end{array}$ & $\begin{array}{l}-0.331 \\
(-2.04)\end{array}$ & $\begin{array}{r}0.208 \\
(1.07)\end{array}$ & $\begin{array}{l}0.014 \\
(3.62)\end{array}$ & 0.243 & 23578 \\
\hline $\begin{array}{l}\text { Higher vocational } \\
\text { (t-val) }\end{array}$ & $\begin{array}{l}2.496 \\
(4.66)\end{array}$ & $\begin{array}{l}-2.727 \\
(-2.90)\end{array}$ & $\begin{array}{l}-0.038 \\
(-0.39)\end{array}$ & $\begin{array}{r}-0.056 \\
(0.56)\end{array}$ & $\begin{array}{r}0.008 \\
(2.47)\end{array}$ & 0.157 & 21396 \\
\hline$(\mathrm{t}-\mathrm{val})$ & $\begin{array}{l}2.354 \\
(8.50)\end{array}$ & $\begin{array}{l}-2.543 \\
(-3.81)\end{array}$ & $\begin{array}{l}-0.364 \\
(-3.64)\end{array}$ & $\begin{array}{r}0.258 \\
(2.53)\end{array}$ & $\begin{array}{r}0.022 \\
(6.75)\end{array}$ & 0.226 & 19645 \\
\hline Women & $\begin{array}{l}3.468 \\
(7.14)\end{array}$ & $\begin{array}{l}-3.178 \\
(-4.11)\end{array}$ & $\begin{array}{l}-0.308 \\
(-2.86)\end{array}$ & $\begin{array}{r}0.250 \\
(1.86)\end{array}$ & $\begin{array}{r}0.004 \\
(1.32)\end{array}$ & 0.228 & 25329 \\
\hline Ability 1 & $\begin{array}{l}3.098 \\
(4.46)\end{array}$ & $\begin{array}{l}-1.633 \\
(-1.03)\end{array}$ & $\begin{array}{l}-0.308 \\
(-2.86)\end{array}$ & $\begin{array}{r}0.250 \\
(1.86)\end{array}$ & $\begin{array}{r}0.004 \\
(1.08)\end{array}$ & 0.172 & 7891 \\
\hline Ability 2 & $\begin{array}{l}-0.089 \\
(-0.05)\end{array}$ & $\begin{array}{r}1.534 \\
(0.60)\end{array}$ & $\begin{array}{l}-0.306 \\
(-3.40)\end{array}$ & $\begin{array}{l}-0.029 \\
(-0.17)\end{array}$ & $\begin{array}{l}0.012 \\
(2.32)\end{array}$ & 0.195 & 8222 \\
\hline Ability 3 & $\begin{array}{l}3.396 \\
(6.36)\end{array}$ & $\begin{array}{r}-2.64 \\
(-4.13)\end{array}$ & $\begin{array}{l}-0.321 \\
(-2.07)\end{array}$ & $\begin{array}{r}0.202 \\
(1.22)\end{array}$ & $\begin{array}{r}0.013 \\
(2.77)\end{array}$ & 0.216 & 12021 \\
\hline Ability 4 & $\begin{array}{r}1.572 \\
(1.84)\end{array}$ & $\begin{array}{l}-1.896 \\
(-1.40)\end{array}$ & $\begin{array}{l}-0.247 \\
(-1.63)\end{array}$ & $\begin{array}{l}0.237 \\
(1.34)\end{array}$ & $\begin{array}{l}0.013 \\
(2.68)\end{array}$ & 0.246 & 16840 \\
\hline Government & $\begin{array}{r}0.717 \\
(0.96)\end{array}$ & $\begin{array}{l}-0.212 \\
(-0.21)\end{array}$ & $\begin{array}{l}-0.357 \\
(-2.84)\end{array}$ & $\begin{array}{l}0.255 \\
(2.05)\end{array}$ & $\begin{array}{r}0.011 \\
(1.96)\end{array}$ & 0.245 & 4255 \\
\hline Education & $\begin{array}{r}3.595 \\
(10.03)\end{array}$ & $\begin{array}{l}-3.025 \\
(-4.93)\end{array}$ & $\begin{array}{l}-0.009 \\
(-0.08)\end{array}$ & $\begin{array}{l}-0.062 \\
(-0.54)\end{array}$ & $\begin{array}{r}0.004 \\
(0.07)\end{array}$ & 0.249 & 6863 \\
\hline Services & $\begin{array}{l}-0.089 \\
(-0.15)\end{array}$ & $\begin{array}{l}-0.199 \\
(-0.32)\end{array}$ & $\begin{array}{l}-0.345 \\
(-2.38)\end{array}$ & $\begin{array}{r}0.551 \\
(4.11)\end{array}$ & $\begin{array}{r}0.027 \\
(6.48)\end{array}$ & 0.237 & 11967 \\
\hline (t-val) & $\begin{array}{r}4.026 \\
(8.28)\end{array}$ & $\begin{array}{l}-3.598 \\
(-3.35)\end{array}$ & $\begin{array}{l}-0.296 \\
(-1.70)\end{array}$ & $\begin{array}{l}-0.153 \\
(-0.93)\end{array}$ & $\begin{array}{r}-0.002 \\
(0.34)\end{array}$ & 0.273 & 7822 \\
\hline Manufacturing & $\begin{array}{l}-0.056 \\
(-0.08)\end{array}$ & $\begin{array}{l}-0.067 \\
(-0.07)\end{array}$ & $\begin{array}{l}-0.445 \\
(-3.09)\end{array}$ & $\begin{array}{r}0.379 \\
(2.98)\end{array}$ & $\begin{array}{l}0.021 \\
(4.32)\end{array}$ & 0.252 & 4342 \\
\hline (t-val) & $\begin{array}{r}0.424 \\
(0.54)\end{array}$ & $\begin{array}{l}-0.324 \\
(-0.27)\end{array}$ & $\begin{array}{l}-0.213 \\
(-1.56)\end{array}$ & $\begin{array}{r}0.262 \\
(1.47)\end{array}$ & $\begin{array}{r}0.012 \\
(3.19)\end{array}$ & 0.171 & 9725 \\
\hline $\begin{array}{l}\text { Experience below } \\
\text { mean }\end{array}$ & 2.695 & -2.427 & -0.260 & 0.219 & 0.008 & 0.207 & 26554 \\
\hline (t-val) & $(6.44)$ & $(-3.78)$ & $(-2.67)$ & $(1.85)$ & $(2.37)$ & & \\
\hline $\begin{array}{l}\text { Experience above mean } \\
(\mathrm{t}-\mathrm{val})\end{array}$ & $\begin{array}{l}3.167 \\
(8.58)\end{array}$ & $\begin{array}{l}-3.009 \\
(-4.34)\end{array}$ & $\begin{array}{l}-0.396 \\
(-3.73)\end{array}$ & $\begin{array}{r}0.232 \\
(1.92)\end{array}$ & $\begin{array}{r}0.017 \\
(5.24)\end{array}$ & 0.229 & 18420 \\
\hline Difficult & 3.171 & -2.904 & -0.366 & 0.200 & 0.013 & 0.224 & 26551 \\
\hline
\end{tabular}




\begin{tabular}{|ll|r|r|r|r|r|r|r|} 
& $(\mathrm{t}-\mathrm{val})$ & $(6.45)$ & $(-3.29)$ & $(-2.89$ & $(1.13)$ & $(3.58)$ & & \\
Not difficult & & 2.226 & -2.212 & -0.233 & 0.298 & 0.009 & 0.225 & 18423 \\
& $(\mathrm{t}-\mathrm{val})$ & $(3.27)$ & $(-2.06)$ & $(-2.27)$ & $(2.61)$ & $(2.90)$ & & \\
\hline
\end{tabular}

$\mathrm{t}$-values based in standard errors clustered by field of education. 


\section{Table 5 Elasticities}

\begin{tabular}{|l|lr|lr|r|}
\hline & Table 1 & Table 2 & & \multicolumn{2}{l|}{ Table 3 } \\
& Aggregate & & OLS & & RE \\
\hline Erisk & & 0.156 & & 0.137 & \\
Eskew & & -0.054 & & -0.052 & 0.146 \\
Grade variance & & -0.108 & & -0.056 & -0.049 \\
Grade skew & & 0.026 & & 0.007 & -0.085 \\
\hline
\end{tabular}

Table 2 and table 3: Based on column A4 
Table 6 Estimating equation (31)

\begin{tabular}{lll}
\hline Wage variables $^{I}: \beta$ & coefficient & t-value \\
\hline Intercept & 1.830 & 3.448 \\
Erisk & 2.941 & 6.79 \\
Eskew & -3.122 & -4.73 \\
Individual grade & 0.011 & 3.64 \\
Male & 0.021 & 5.57 \\
HBO-level & -0.078 & -7.83 \\
Employer risk: $\delta$ & & \\
\hline Grade variance $\left(\delta_{1}\right)$ & -0.887 & -9.63 \\
Grade skew $\left(\delta_{2}\right)$ & 0.619 & 4.03 \\
Risk sharing ${ }^{2)} \theta_{i}: \alpha$ & & \\
\hline Intercept & -1.728 & 05.84 \\
HBO level & 0.48 & 2.03 \\
Industry (reference:government) & & \\
Education & -3.246 & -1.18 \\
Business services & 2.028 & 5.74 \\
Financial services & 0.838 & 3.19 \\
Health and personal care & -1.501 & -2.42 \\
Manufacturing & 1.045 & 4.45 \\
Other & 1.908 & 5.80 \\
\hline
\end{tabular}

$\mathrm{N}=44947 \mathrm{R}^{2}=0.204 \quad \mathrm{t}$-values based on standard errors clustered by fields of education

Characteristics $\theta_{i}$.

Mean $=0.317 ;$ Minimum $=0.0003 ;$ Maximum $=0.959 ;$ Standard Deviation $=0.276$

1) also contains gender, age, parent education, months since graduation, dummy for Ph.D. student, higher vocational grade and job below level of eduction

2) also contains 3 regional dummies, vocational graduate, job below level of education and months since graduation 
Figure 1A Mean Ln hourly wage and grade variance, by education

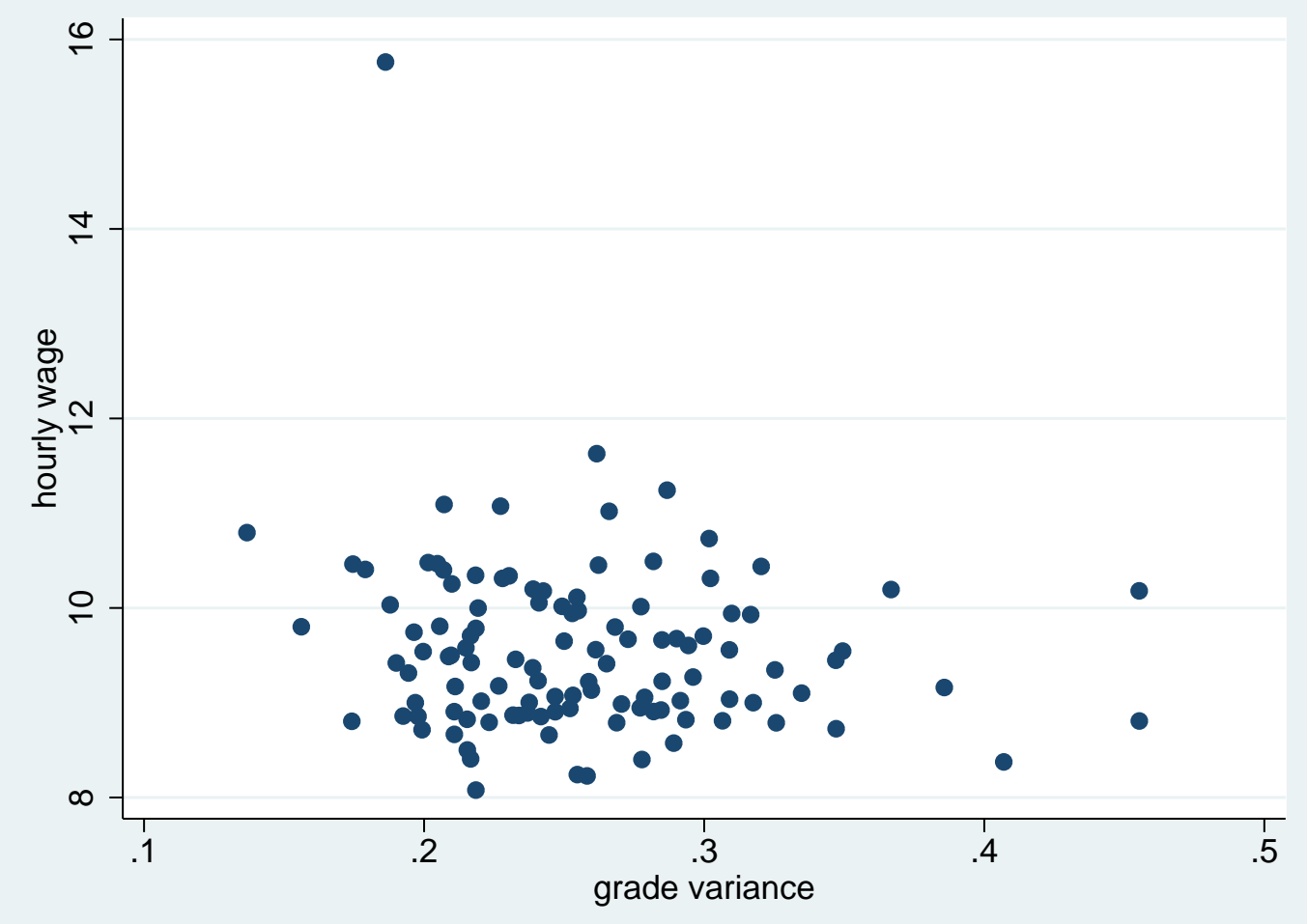


Figure 1B Mean Ln hourly wage and grade skewness, by education

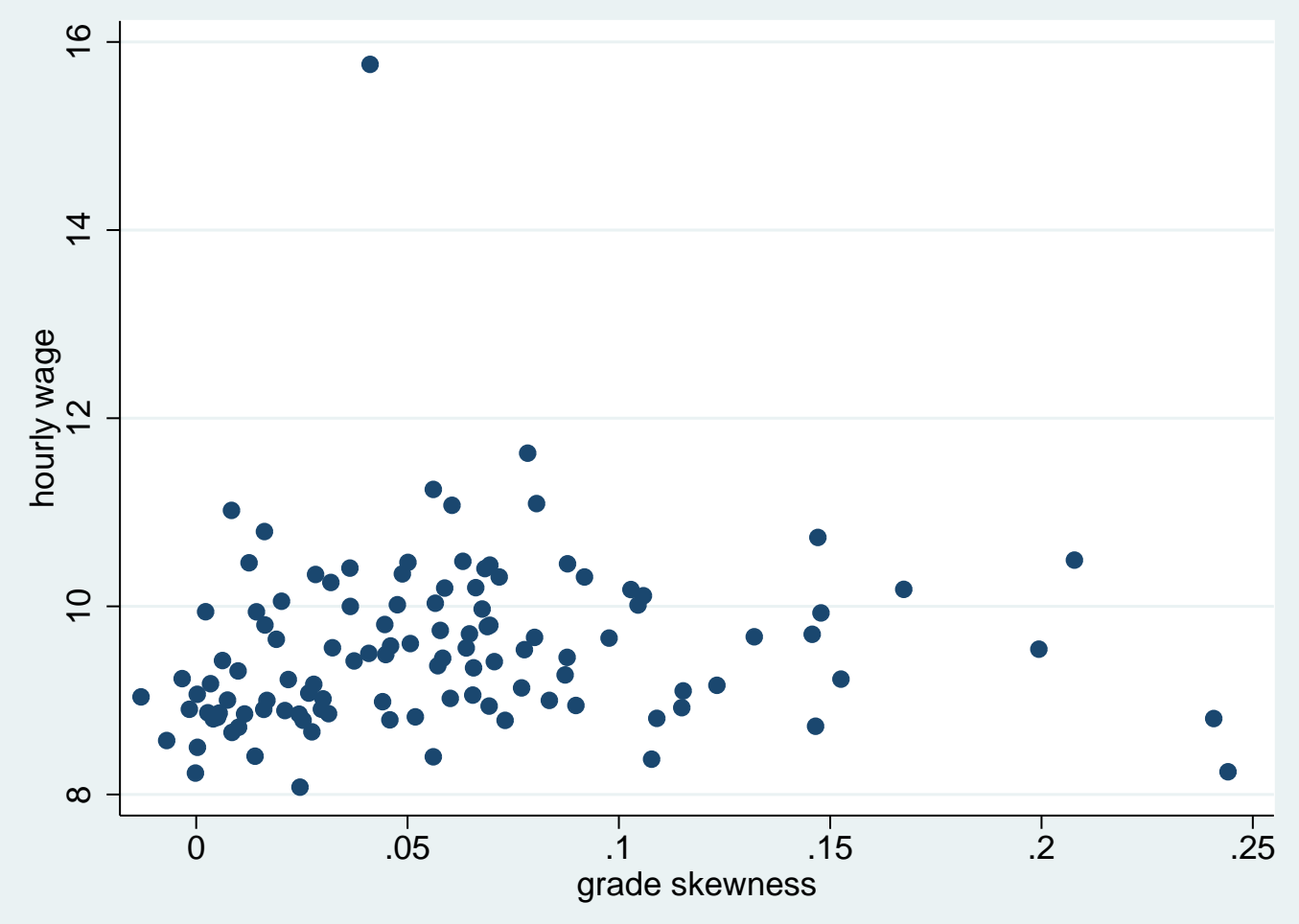


Figure 2. Risk shifting year dummies and national unemployment rate (source: dummies regression (25);unemployment rate: $\mathrm{CPB}$ )

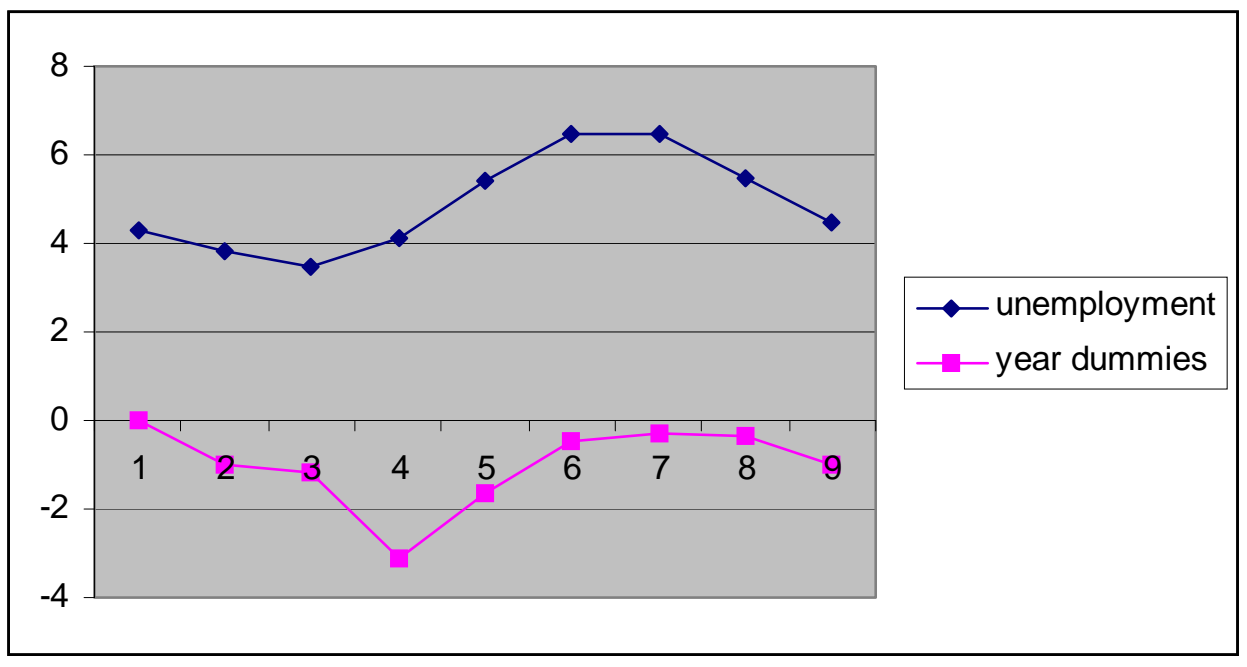




\section{Appendix. Data description}

Key variables

Individual Grade

Gradevar

Gradeskew

Erisk

Eskew

Residuals from earnings function:

In wage on dummies for education,

cohort and region
Mean of individuals' average exam grade, self-reported

Variance of individuals' average exam grade, by field of study

Skew (third moment) of individuals' average exam grade, by field of study

Residual earnings variance, by field of study

Residual earnings skew (third moment), by field of study 


\section{Correlations}

\begin{tabular}{lrlrrrr}
\hline & \multicolumn{1}{l}{$\begin{array}{l}\text { Hourly } \\
\text { wage }\end{array}$} & $\begin{array}{l}\text { Ln } \\
\text { hourly } \\
\text { wage }\end{array}$ & Erisk & Eskew & \multicolumn{1}{l}{$\begin{array}{l}\text { Grade } \\
\text { var. }\end{array}$} & $\begin{array}{l}\text { Grade } \\
\text { skew }\end{array}$ \\
\hline Hourly wage & 1.000 & & & & & \\
Ln hourly wage & 0.995 & 1.000 & & & & \\
Erisk & 0.349 & 0.333 & 1.000 & & & \\
Eskew & 0.038 & 0.056 & 0.739 & 1.000 & & \\
Grade variance & -0.058 & -0.052 & 0.359 & 0.438 & 1.000 & \\
Grade skew & 0.122 & 0.132 & 0.275 & 0.345 & 0.658 & 1.000 \\
\hline
\end{tabular}




\section{Key data by education}

\section{VOCATIONAL}

Business Economics/Business Sciences

\section{Commerce}

Business Informatics

Communication

Accountancy

International Business \& Languages

Tourism \& Leisure

Hotel Management

Small Business and Retail Management

Management, Economics \& Law

Logistics \& Economics

Facility Services

Journalism

Business Management

Fiscal Economics

European Professions

Leisure Management

International Business \& Management

Real Estate

Personnel \& Labour

Socio-Cultural Studies

Social Work \& Services

Social Pedagogy

Socio-Legal Services

Information Management

Creative Therapy

Medical LaboratoryTechnician

Nursing

Physiotherapy
Grade var Grade skew

0,247

0,285

0,194

0,198

0,270

0,245

0,218

0,269

0,291

0,242

0,237

0,211

0,285

0,193

0,347

0,252

0,258

0,211

0,217

0,220

0,199

0,209

0,232

0,211

0,234

0,200

0,278

0,259

0,266
Erisk

$$
0,016
$$

0,115

0,010

0,011

0,044

0,008

0,025

0,025

0,060

0,024

0,021

0,027

0,153

0,031

0,058

0,069

0,000

$-0,002$

0,014

0,030

0,010

0,045

$-0,003$

$-0,028$

0,005

0,078

0,056

0,022

0,008
0,036

0,048

0,046

0,043

0,041

0,033

0,039

0,046

0,055

0,045

0,044

0,043

0,050

0,025

0,055

0,069

0,048

0,064

0,052

0,037

0,049

0,043

0,034

0,034

0,045

0,049

0,036

0,036

0,083

\section{Esk}

0,010

0,020

0,013

0,013

0,010

0,010

0,008

0,016

0,018

0,016

0,019

0,015

0,014

0,004

0,017

0,037

0,016

0,017

0,012

0,007

0,017

0,016

0,008

0,010

0,016

0,014

0,020

0,016

0,026
2,185

2,186

2,232

2,181

2,194

2,157

2,089

2,173

2,199

2,180

2,183

2,159

2,222

2,182

2,239

2,191

2,108

2,187

2,129

2,197

2,165

2,249

2,183

2,218

2,183

2,255

2,128

2,222

2,399
565

501

549

480

431

368

421

409

218

461

541

549

462

118

220

153

154

62

73

514

423

550

766

381

327

110

473

708

534 
Speech Therapy

Nutrition \& Dietetics

Ergotherapy

Medical Imaging \& Radiotherapy

Oral Hygiene

Environmental Management

Agri-Business

Animal Husbandry

Food Technology

Primary School Teacher

Physical Education Teacher, Grade 1

Dutch Language Teacher

Economics Teacher (General \& Business)

Special Needs Teacher

Social Studies Teacher

Education Teacher

Math/Physics Teacher

Geography/History Teacher

Arts \& Crafts Teacher

English/French/German Language Teacher

Visual Arts \& Design Teacher

Music Teacher

Drama Teacher

Chemical Technician

Structural Engineering

Electrical Engineering

Civil Engineering

Chemical Engineering

Applied Informatics

Mechanical Engineering

Applied Physics

Fashion Management \& Technology

$\begin{array}{rrrllllr}0,296 & 0,087 & 0,058 & 0,021 & 2,227 & 0 & 7,256 & 412 \\ 0,253 & 0,027 & 0,052 & 0,022 & 2,206 & 1 & 7,000 & 467 \\ 0,261 & 0,032 & 0,053 & 0,021 & 2,258 & 0 & 7,150 & 535 \\ 0,347 & 0,147 & 0,016 & 0,003 & 2,167 & 1 & 7,092 & 184 \\ 0,179 & 0,036 & 0,068 & 0,039 & 2,343 & 1 & 7,218 & 85 \\ 0,238 & 0,007 & 0,039 & 0,008 & 2,199 & 1 & 6,929 & 380 \\ 0,227 & 0,003 & 0,042 & 0,017 & 2,217 & 1 & 6,900 & 306 \\ 0,215 & 0,000 & 0,060 & 0,025 & 2,140 & 1 & 6,955 & 322 \\ 0,197 & 0,017 & 0,029 & 0,004 & 2,200 & 1 & 6,837 & 95 \\ 0,294 & 0,051 & 0,041 & 0,022 & 2,261 & 0 & 7,330 & 683 \\ 0,175 & 0,013 & 0,070 & 0,016 & 2,348 & 1 & 6,996 & 374 \\ 0,196 & 0,058 & 0,062 & 0,023 & 2,275 & 0 & 7,237 & 251 \\ 0,217 & 0,006 & 0,053 & 0,019 & 2,241 & 1 & 7,011 & 307 \\ 0,273 & 0,080 & 0,032 & 0,008 & 2,264 & 0 & 7,471 & 277 \\ 0,174 & 0,004 & 0,044 & 0,010 & 2,176 & 1 & 7,046 & 87 \\ 0,241 & -0,003 & 0,037 & 0,006 & 2,223 & 0 & 7,409 & 208 \\ 0,367 & 0,059 & 0,054 & 0,015 & 2,322 & 1 & 7,170 & 350 \\ 0,253 & 0,002 & 0,077 & 0,021 & 2,296 & 1 & 7,025 & 424 \\ 0,215 & 0,052 & 0,108 & 0,049 & 2,175 & 1 & 7,300 & 65 \\ 0,320 & 0,069 & 0,083 & 0,018 & 2,345 & 0 & 7,295 & 469 \\ 0,455 & 0,241 & 0,099 & 0,057 & 2,176 & 0 & 7,390 & 295 \\ 0,455 & 0,167 & 0,095 & 0,028 & 2,320 & 1 & 7,814 & 153 \\ 0,407 & 0,108 & 0,049 & 0,028 & 2,125 & 1 & 7,692 & 39 \\ 0,289 & -0,007 & 0,037 & 0,011 & 2,149 & 1 & 6,975 & 223 \\ 0,223 & 0,046 & 0,035 & 0,010 & 2,174 & 1 & 7,062 & 438 \\ 0,260 & 0,077 & 0,031 & 0,007 & 2,214 & 1 & 7,144 & 353 \\ 0,293 & 0,005 & 0,035 & 0,011 & 2,175 & 1 & 7,079 & 399 \\ 0,279 & 0,065 & 0,029 & 0,006 & 2,202 & 1 & 7,091 & 532 \\ 0,325 & 0,066 & 0,046 & 0,015 & 2,235 & 1 & 7,123 & 500 \\ 0,277 & 0,090 & 0,041 & 0,015 & 2,192 & 1 & 7,053 & 385 \\ 0,318 & 0,084 & 0,024 & 0,003 & 2,197 & 1 & 7,229 & 83 \\ 0,255 & 0,244 & 0,030 & 0,005 & 2,108 & 1 & 7,168 & 110\end{array}$




\section{Car Mechanics \\ UNIVERSITY}

Dutch

English

Other Languages

Philosophy/Theology

History

Language \& Culture

Art History \& Archeology

Corporate Communications

European Studies

Film, Television \& Theatre Studies

Information Science

Chemistry

Computer Science

Biology

Pharmacy

Pure Mathematics/Physics

Agricultural Science

Chemical/Technical Agri-Sciences

Architecture

Mechanical Engineering

Electrical Engineering

Chemical Engineering

Civil Engineering

Technology \& Management

Industrial Design

Aerospace Engineering

Applied Computer Science

Applied Mathematics/Physics

Economics

Business Science

\begin{tabular}{|c|c|c|c|c|c|c|c|}
\hline 0,309 & $-0,013$ & 0,054 & 0,027 & 2,204 & 1 & 7,018 & 84 \\
\hline Grade var & Grade skew & Erisk & Eskew & Hourly wage & DumDiff & Grade & $\mathbf{N}$ \\
\hline 0,268 & 0,069 & 0,052 & 0,019 & 2,283 & 0 & 7,336 & 451 \\
\hline 0,309 & 0,064 & 0,073 & 0,032 & 2,258 & 0 & 7,351 & 345 \\
\hline 0,290 & 0,132 & 0,072 & 0,034 & 2,268 & 0 & 7,323 & 285 \\
\hline 0,310 & 0,014 & 0,076 & 0,036 & 2,296 & 1 & 7,716 & 141 \\
\hline 0,300 & 0,146 & 0,070 & 0,029 & 2,273 & 1 & 7,387 & 475 \\
\hline 0,265 & 0,071 & 0,064 & 0,036 & 2,243 & 0 & 7,200 & 358 \\
\hline 0,282 & 0,030 & 0,046 & 0,011 & 2,187 & 0 & 7,435 & 216 \\
\hline 0,190 & 0,037 & 0,050 & 0,028 & 2,241 & 1 & 7,056 & 293 \\
\hline 0,250 & 0,019 & 0,090 & 0,081 & 2,262 & 1 & 6,945 & 64 \\
\hline 0,247 & 0,000 & 0,061 & 0,015 & 2,204 & 1 & 7,259 & 108 \\
\hline 0,233 & 0,088 & 0,031 & 0,004 & 2,247 & 0 & 7,258 & 209 \\
\hline 0,307 & 0,109 & 0,056 & 0,030 & 2,173 & 0 & 7,388 & 449 \\
\hline 0,349 & 0,199 & 0,052 & 0,023 & 2,252 & 0 & 7,490 & 204 \\
\hline 0,326 & 0,073 & 0,061 & 0,037 & 2,174 & 0 & 7,389 & 669 \\
\hline 0,262 & 0,078 & 0,049 & 0,009 & 2,452 & 0 & 7,283 & 417 \\
\hline 0,386 & 0,123 & 0,060 & 0,022 & 2,214 & 1 & 7,545 & 434 \\
\hline 0,215 & 0,046 & 0,047 & 0,020 & 2,260 & 0 & 7,246 & 303 \\
\hline 0,210 & 0,041 & 0,053 & 0,020 & 2,251 & 1 & 7,214 & 610 \\
\hline 0,217 & 0,065 & 0,033 & 0,008 & 2,270 & 1 & 7,224 & 665 \\
\hline 0,262 & 0,088 & 0,045 & 0,012 & 2,345 & 0 & 7,430 & 590 \\
\hline 0,302 & 0,092 & 0,059 & 0,035 & 2,334 & 0 & 7,433 & 358 \\
\hline 0,277 & 0,105 & 0,050 & 0,017 & 2,304 & 0 & 7,391 & 471 \\
\hline 0,188 & 0,057 & 0,036 & 0,012 & 2,307 & 1 & 7,216 & 619 \\
\hline 0,137 & 0,016 & 0,046 & 0,019 & 2,378 & 1 & 7,133 & 606 \\
\hline 0,156 & 0,016 & 0,039 & 0,012 & 2,280 & 0 & 7,165 & 328 \\
\hline 0,230 & 0,028 & 0,028 & 0,004 & 2,336 & 1 & 7,478 & 113 \\
\hline 0,249 & 0,048 & 0,038 & 0,017 & 2,301 & 0 & 7,462 & 235 \\
\hline 0,285 & 0,098 & 0,050 & 0,016 & 2,269 & 0 & 7,506 & 545 \\
\hline 0,228 & 0,072 & 0,045 & 0,014 & 2,333 & 1 & 7,089 & 1.254 \\
\hline 0,205 & 0,050 & 0,048 & 0,017 & 2,348 & 1 & 7,072 & 631 \\
\hline
\end{tabular}


Econometrics

Fiscal Economics

Business Studies

Dutch Law

Notarial Law

Fiscal Law

Healthcare

Medicine

Dentistry

Biomedical Science

Veterinary Science

Sociology

Psychology

Political Science

Education Science

Applied Education Science

Cultural Anthropology

Communication

Socio-Cultural Science

Public Administration

Human Geography \& Planning

TOTAL VOCATIONAL (weighted) TOTAL UNIVERSITY (weighted) TOTAL (weighted)

\section{SUBPOPULATIONS}

All

University

Higher vocational

Men

Women

\begin{tabular}{|c|c|c|c|c|c|c|c|}
\hline 0,302 & 0,147 & 0,060 & 0,022 & 2,374 & 0 & 7,319 & 434 \\
\hline 0,227 & 0,061 & 0,036 & 0,010 & 2,402 & 1 & 6,948 & 162 \\
\hline 0,201 & 0,063 & 0,049 & 0,014 & 2,349 & 0 & 7,137 & 610 \\
\hline 0,243 & 0,103 & 0,041 & 0,014 & 2,320 & 1 & 7,124 & 908 \\
\hline 0,255 & 0,106 & 0,040 & 0,011 & 2,314 & 1 & 7,018 & 410 \\
\hline 0,207 & 0,081 & 0,042 & 0,015 & 2,405 & 1 & 6,995 & 443 \\
\hline 0,241 & 0,020 & 0,058 & 0,020 & 2,307 & 0 & 7,182 & 625 \\
\hline 0,287 & 0,056 & 0,048 & 0,013 & 2,420 & 1 & 7,237 & 889 \\
\hline 0,186 & 0,041 & 0,129 & $-0,001$ & 2,757 & 1 & 7,162 & 111 \\
\hline 0,335 & 0,115 & 0,050 & 0,020 & 2,209 & 0 & 7,328 & 487 \\
\hline 0,282 & 0,208 & 0,034 & 0,006 & 2,351 & 0 & 7,114 & 223 \\
\hline 0,317 & 0,148 & 0,049 & 0,010 & 2,294 & 1 & 7,236 & 388 \\
\hline 0,255 & 0,068 & 0,068 & 0,030 & 2,300 & 0 & 7,299 & 902 \\
\hline 0,218 & 0,049 & 0,055 & 0,018 & 2,337 & 0 & 7,299 & 369 \\
\hline 0,210 & 0,032 & 0,062 & 0,028 & 2,328 & 0 & 7,173 & 574 \\
\hline 0,239 & 0,066 & 0,051 & 0,020 & 2,323 & 0 & 7,304 & 334 \\
\hline 0,239 & 0,057 & 0,064 & 0,030 & 2,235 & 0 & 7,269 & 316 \\
\hline 0,206 & 0,045 & 0,056 & 0,026 & 2,284 & 1 & 7,155 & 544 \\
\hline 0,219 & 0,036 & 0,053 & 0,026 & 2,301 & 0 & 7,178 & 662 \\
\hline 0,207 & 0,068 & 0,044 & 0,013 & 2,341 & 1 & 7,152 & 822 \\
\hline 0,218 & 0,069 & 0,042 & 0,014 & 2,280 & 1 & 7,092 & 919 \\
\hline 0,258 & 0,044 & 0,045 & 0,016 & 2,217 & 0,499 & 7,104 & 21396 \\
\hline 0,245 & 0,074 & 0,050 & 0,019 & 2,318 & 0,565 & 7,211 & 23578 \\
\hline 0,253 & 0,054 & 0,047 & 0,017 & 2,252 & 0,538 & 7,141 & 44974 \\
\hline e var & skew & Erisk & Eskew & Hourly wage & \multicolumn{2}{|c|}{ DumDiff Ind. Grade } & $\mathbf{N}$ \\
\hline 0,253 & 0,054 & 0,047 & 0,017 & 2,252 & 0,538 & 7,141 & 44974 \\
\hline 0,245 & 0,074 & 0,050 & 0,019 & 2,318 & 0,565 & 7,211 & 23578 \\
\hline 0,258 & 0,044 & 0,045 & 0,016 & 2,217 & 0,499 & 7,104 & 21396 \\
\hline 0,253 & 0,058 & 0,046 & 0,016 & 2,260 & 0,763 & 7,076 & 19645 \\
\hline 0,254 & 0,051 & 0,047 & 0,018 & 2,247 & 0,487 & 7,188 & 25329 \\
\hline
\end{tabular}




Ability 1 (lowest)
Ability 2
Ability 3
Ability 4 (highest)
Government
Education
Services
Care
Manufacturing
Other
Experience below mean
Experience above mean
Difficult
Easy

$\begin{array}{lllllllr}0,254 & 0,028 & 0,045 & 0,017 & 2,234 & 0,318 & 7,166 & 7891 \\ 0,245 & 0,048 & 0,045 & 0,016 & 2,206 & 0,744 & 7,047 & 8222 \\ 0,258 & 0,069 & 0,048 & 0,017 & 2,265 & 0,716 & 7,101 & 12021 \\ 0,257 & 0,076 & 0,049 & 0,017 & 2,309 & 0,663 & 7,250 & 16840 \\ 0,240 & 0,057 & 0,046 & 0,016 & 2,294 & 0,721 & 7,123 & 4255 \\ 0,280 & 0,060 & 0,050 & 0,021 & 2,267 & 0,248 & 7,345 & 6863 \\ 0,244 & 0,057 & 0,045 & 0,015 & 2,245 & 0,829 & 7,052 & 11967 \\ 0,251 & 0,035 & 0,047 & 0,016 & 2,290 & 0,325 & 7,181 & 7822 \\ 0,255 & 0,065 & 0,045 & 0,016 & 2,250 & 0,662 & 7,079 & 4342 \\ 0,253 & 0,058 & 0,047 & 0,017 & 2,199 & 0,766 & 7,100 & 9725 \\ 0,253 & 0,052 & 0,046 & 0,017 & 2,231 & 0,593 & 7,149 & 26554 \\ 0,254 & 0,059 & 0,047 & 0,017 & 2,287 & 0,618 & 7,128 & 18420 \\ 0,248 & 0,054 & 0,046 & 0,015 & 2,257 & 1,000 & 7,060 & 26651 \\ 0,261 & 0,054 & 0,047 & 0,019 & 2,247 & 0,000 & 7,249 & 18423\end{array}$

